\title{
Multi-modal albedo distributions in the ablation area of the southwestern Greenland Ice Sheet
} \author{
and C. A. Shuman ${ }^{4,7}$ \\ ${ }^{1}$ Department of Geography, Rutgers, The State University of New Jersey, 54 Joyce Kilmer Avenue, \\ Piscataway, NJ 08854-8045, USA \\ ${ }^{2}$ Department of Geography, University of California, Los Angeles, 1255 Bunche Hall, \\ P. O. Box 951524, Los Angeles, CA 90095-1524, USA \\ ${ }^{3}$ Department of Environmental Sciences, Rutgers, The State University of New Jersey, \\ 14 College Farm Rd, New Brunswick, NJ 08901-8551, USA \\ ${ }^{4}$ Cryospheric Sciences Laboratory, NASA Goddard Space Flight Center, 8800 Greenbelt Road, \\ Greenbelt, MD, 20771, USA \\ ${ }^{5}$ Biospheric Sciences Laboratory, NASA Goddard Space Flight Center, 8800 Greenbelt Road, \\ Greenbelt, MD, 20771, USA \\ ${ }^{6}$ Science Systems and Applications, Inc., 10210 Greenbelt Rd, Lanham, MD, 20706, USA \\ ${ }^{7}$ Joint Center for Earth Systems Technology (JCET), University of Maryland, Baltimore County, \\ 1000 Hilltop Circle, Baltimore, MD, 21250, USA \\ *now at: National Snow and Ice Data Center, University of Colorado, 1540 30th Ave., \\ Boulder CO 80303, USA
}

S. E. Moustafa ${ }^{1}$, A. K. Rennermalm ${ }^{1}$, L. C. Smith ${ }^{2}$, M. A. Miller ${ }^{3}$, J. R. Mioduszewski ${ }^{1}$, L. S. Koenig ${ }^{4,}{ }^{*}$, M. G. Hom ${ }^{5,6}$,

Correspondence to: S. E. Moustafa (samiah.moustafa@rutgers.edu)

Received: 4 August 2014 - Published in The Cryosphere Discuss.: 5 September 2014 Revised: 1 March 2015 - Accepted: 26 March 2015 - Published: 7 May 2015

\begin{abstract}
Surface albedo is a key variable controlling solar radiation absorbed at the Greenland Ice Sheet (GrIS) surface and, thus, meltwater production. Recent decline in surface albedo over the GrIS has been linked to enhanced snow grain metamorphic rates, earlier snowmelt, and amplified meltalbedo feedback from atmospheric warming. However, the importance of distinct surface types on ablation area albedo and meltwater production is still relatively unknown. In this study, we analyze albedo and ablation rates using in situ and remotely sensed data. Observations include (1) a new highquality in situ spectral albedo data set collected with an Analytical Spectral Devices Inc. spectroradiometer measuring at $325-1075 \mathrm{~nm}$ along a $1.25 \mathrm{~km}$ transect during 3 days in June 2013; (2) broadband albedo at two automatic weather stations; and (3) daily MODerate Resolution Imaging Spectroradiometer (MODIS) albedo (MOD10A1) between 31 May and 30 August 2012 and 2013. We find that seasonal ablation area albedos in 2013 have a bimodal distribution, with snow
\end{abstract}

and ice facies characterizing the two peaks. Our results show that a shift from a distribution dominated by high to low albedos corresponds to an observed melt rate increase of $51.5 \%$ (between 10-14 July and 20-24 July 2013). In contrast, melt rate variability caused by albedo changes before and after this shift was much lower and varied between $\sim 10$ and $30 \%$ in the melting season. Ablation area albedos in 2012 exhibited a more complex multimodal distribution, reflecting a transition from light to dark-dominated surface, as well as sensitivity to the so called "dark-band" region in southwest Greenland. In addition to a darkening surface from ice crystal growth, our findings demonstrate that seasonal changes in GrIS ablation area albedos are controlled by changes in the fractional coverage of snow, bare ice, and impurity-rich surface types. Thus, seasonal variability in ablation area albedos appears to be regulated primarily as a function of bare ice expansion at the expense of snow, surface meltwater ponding, and melting of outcropped ice layers enriched with mineral materials, en- 
abling dust and impurities to accumulate. As climate change continues in the Arctic region, understanding the seasonal evolution of ice sheet surface types in Greenland's ablation area is critical to improve projections of mass loss contributions to sea level rise.

\section{Introduction}

Surface albedo, defined as the bihemispheric reflectance integrated across the visible and near-infrared wavelengths (Schaepman-Strub et al., 2006), is a key variable controlling Greenland Ice Sheet (GrIS) surface melting. During the melt season, surface albedo modulates absorbed solar radiation at the ice surface and, consequently, the surface energy and mass balance of the ice sheet (Cuffey and Paterson, 2010). Over the last decade, an observed decline in albedo has been linked to less summer snow cover, expansion of bare ice area, and enhanced snow grain metamorphic rates from atmospheric warming, amplified by the melt-albedo feedback (Box et al., 2012; Stroeve et al., 2013; Tedesco et al., 2011). This positive feedback involves increased melting and exposure of bare ice, impurities, and meltwater ponding, reducing surface albedo and, by increasing solar radiation absorption, accelerating melt further (Box et al., 2012; Tedesco et al., 2011).

The GrIS surface has a wide range of surface types with different albedos, including snow, ice, dust and sedimentrich impurities, cryoconite holes, melt ponds, and streams. Yet, the importance of these surface types on ablation area albedos and thus, meltwater production over the melt season is still relatively unresolved (Rennermalm et al., 2013). Current state-of-the-art surface mass balance (SMB) models, such as Modèle Atmosphérique Régionale (MAR) v3.2 and Regional Atmospheric Climate MOdel (RACMO2), consider some variability in surface types by including the presence of meltwater ponding, snow, and bare ice surfaces to characterize seasonal variations in ablation area albedo (Alexander et al., 2014; Van Angelen et al., 2012). Furthermore, RACMO2 considers the presence of black carbon concentrations on snow and is capable of utilizing realistic MODerate Resolution Imaging Spectroradiometer (MODIS) background albedo data (Van Angelen et al., 2012), thereby representing the impact of surface types spatially aggregated to the MODIS resolution. However, few studies have utilized these modeling tools to understand how the distributions of surface types are changing ablation area albedo (e.g., Alexander et al. 2014). This is increasingly important due to enhanced surface melt associated with anomalously warm atmospheric circulation patterns in 2007-2012 (Hall et al., 2013; Nghiem et al., 2012; Tedesco et al., 2013) that may become more frequent in the future. Additionally, some studies suggest that a new control of ice sheet albedo is the deposition and accumulation of light-absorbing impurities advected from snow-free areas and forest fires outside of Greenland (Dumont et al., 2014; Keegan et al., 2014).

The large-scale decline in albedos has been greatest in southwest Greenland $(-0.04$ to -0.16 per decade trend in June and August for 2000 to 2012, respectively; Stroeve et al., 2013). This is related to stronger warming trends $\left(2-4^{\circ} \mathrm{C}\right.$ in some regions; Hanna et al., 2014), early melt onset, a lack of wintertime accumulation (van den Broeke et al., 2008), expansion of bare ice area (Tedesco et al., 2011), high concentration of impurities (cryoconite, dust, and soot), melting of outcropped ice layers enriched with mineral content (Wientjes and Oerlemans, 2010; Wientjes et al., 2011), and enhanced meltwater production and runoff (e.g., Mernild et al., 2012). Seasonal changes in the distribution of different surface types in southwest Greenland's ablation area have considerable influence on the spatiotemporal variability of surface albedos (Chandler et al., 2015; Knap and Oerlemanns, 1996; Konzelmann and Braithwaite, 1995). During the melt season, surface albedo decreases as cryoconite hole coverage increases (Chandler et al., 2015), melt ponds and supraglacial rivers form efficient drainage networks (Lampkin and VanderBerg, 2013; Kang and Smith, 2013; Smith et al., 2015), crevasses and other types of roughness begin to form, and impurities accumulate from exposure of the underlying ice surface (Wientjes and Oerlemans, 2010). Albedo in western Greenland's ablation area averages around $\sim 0.41$ for the $\mathrm{du}-$ ration of the melt season (Wientjes et al., 2011), but can vary from $>0.80$ for fresh snow to $0.30-0.60$ for bare ice (Cuffey and Patterson, 2010) and $\sim 0.10$ for cryoconite surfaces (Bøggild et al., 2010; Chandler et al., 2015; Knap and Oerlemans, 1996). Furthermore, negative albedo trends since 2000 (Box et al., 2012) are linked to an expansion of areas of ablation relative to accumulation facies.

Changes in surface albedo are typically characterized from the MODIS and the Advanced Very High Resolution Radiometer (AVHRR) satellite sensors (e.g., Chandler et al., 2015; Stroeve et al., 2013; Wang et al., 2012; Wright et al., 2014) or modeled with regional climate models (RCMs) such as RACMO2 (Van Meijgaard et al., 2008) and MAR (Fettweis, 2007). Remotely sensed and modeled albedo has been validated with ground measurements from dispersed Greenland Climate Network automatic weather stations (GC-Net AWS; Knap and Oerlemans, 1996; Steffen and Box, 2001). These comparisons reveal that satellite products provide reasonable albedo estimates (Box et al., 2012; Stroeve et al., 2005, 2006, 2013), although discrepancies between different MODIS albedo products have been identified (Alexander et al., 2014). Despite this, RCM surface albedos remain represented in relatively simplistic terms, particularly in regions that frequently experience prolonged bare ice exposure like southwest Greenland (Fettweis et al, 2011; Fitzgerald et al., 2012; Rae et al., 2012; Van Angelen et al., 2012). This is attributed to a lack of surface roughness in the RCMs (Ettema et al., 2010) and relatively simplistic bare ice and impurity albedo schemes (Alexander et al., 2014), resulting in 
large inter-model differences in runoff ( $42 \%$ variance; Vernon et al., 2013) despite the existence of spatially distributed ice albedo schemes and inclusion of black carbon contaminants on snow surfaces (Van Angelen et al., 2012). Recent surface albedo observations and snow model simulations of impurity-rich surfaces have been linked to enhanced ice sheet melt (Chandler et al., 2015; Dumont et al., 2014; Keegan et al., 2014), suggesting that incorporating seasonal changes in the albedo distribution of distinct surface types might improve accuracy of modeled meltwater runoff and GrIS sea level rise contributions. These findings point to the importance of a detailed assessment of high spectral, spatial, and temporal resolution albedo data to quantify how different surface types control ablation area albedo and therefore melt.

In this study, we report the results of an assessment of ablation area albedo along the southwestern GrIS for the 2012 and 2013 melt seasons. We use (1) a new high-quality in situ spectral albedo data set collected with an Analytical Spectral Devices Inc. (ASD) spectroradiometer measuring over a wavelength range of $325-1075 \mathrm{~nm}$ along a $1.25 \mathrm{~km}$ transect during 3 days in June 2013; (2) in situ broadband albedos at two automatic weather stations; and (3) daily MODIS albedo (MOD10A1) product (Hall et al., 2012) between 31 May and 30 August 2012 and 2013 to investigate how ice sheet surface types influence surface albedo and ablation rates; and (4) summer seasonal changes in surface type coverage reported in literature. First, we describe the collection of high-quality in situ spectral albedos, automatic weather station broadband albedos, and ablation stake measurements collected during early 2013 melt season along a fixed transect in the GrIS ablation area. Second, from the MODIS daily albedo data we estimate seasonal changes in the albedo distributions. These distributions were compared with seasonal changes in computed albedo distributions derived by using in situ and literature values of albedos for distinct surface type and fractional area of surface types from a nearby site $(1030 \mathrm{~m}$ a.s.1.; reported by Chandler et al., 2015). Third, the impact of changing albedo and surface type coverage on surface melt was quantified and compared with transect ablation stake measurements. Finally, we compare these 2013 results with 2012 MOD10A1 data to better understand the overall frequency distribution, spatiotemporal variability, and ablation rates associated with dominant surface types in southwest Greenland's ablation area. This study presents the first high spatial, temporal, and spectral resolution albedo data set collected in the southwestern GrIS ablation area.

\section{Study site description}

The study site is located on the southwestern GrIS approximately $30 \mathrm{~km}$ northeast of Kangerlussuaq, Greenland (Fig. 1). Albedo measurements were collected along a $1.25 \mathrm{~km}$ transect situated between $\sim 510$ and $590 \mathrm{ma}$ a.s.1., well within the ablation area for this region (mean equilib- rium line altitude of $1553 \mathrm{~m}$ a.s.l.; van de Wal et al., 2012). Two meteorological stations, referred to as Base Met and Top Met stations, were installed near the transect end points by Site E and A (Fig. 1), respectively, to derive independent measurements of in situ broadband albedos (300-1100 nm), hereafter $\alpha_{\text {base }}$ and $\alpha_{\text {top. }}$. In addition, ablation stakes were installed at five sites along the albedo transect and by the Base Met Station to measure ice surface ablation rates. Ice sheet surface types examined included white ice, shallow supraglacial streams, and dirty ice, where dirty ice was qualitatively distinguished from white ice based on visible surface sediments. Visual assessment in the study area revealed that snow had melted before mid-June and no snowfall events occurred between 8 and 26 June 2013. A few small melt ponds $\left(<1 \mathrm{~km}^{2}\right)$ were observed in the study area but likely not in sufficient quantity to explain discrepancies between in situ and MODIS albedo-derived estimates.

\section{Methods}

\subsection{Field spectroscopy measurements}

High spatial ( 10 m posting), temporal (1-2 days), and spectral $(1 \mathrm{~nm})$ resolution spectral albedo measurements, hereafter $\alpha_{\mathrm{ASD}}$, were measured at 325-1075 nm using an ASD Fieldspec HandHeld 2 Spectroradiometer (PANalytical, formerly ASD Inc.). The ASD was mounted on a tripod at $0.4 \mathrm{~m}$ distance, fitted with a Remote Cosine Receptor (RCR) foreoptic (with no other foreoptic attached; i.e., bare fiber), and had a $25^{\circ}$ field of view corresponding to a spot size of $\sim 0.18 \mathrm{~m}$ diameter on the surface.

Spectral albedos were measured along the transect starting at Site E and ending at Site A on 16, 17, 19, 21, 24, and 25 June 2013 between 10:00 and 18:00 local time (12:00-20:00 GMT). After rigorous quality control (see Appendix A and B), only transect observations made on 16, 19, and 25 June were used in analyses. Broadband $\alpha_{\text {ASD }}$ were calculated as a weighted average based on their spectral response curve and the amount of incoming solar radiation over the entire spectral range at each site along the transect. These measurements were compared with MOD10A1 and meteorological station data, as described in Sect. 3.3.

\subsection{Continuous broadband albedo measurements at meteorological stations}

Daily average broadband albedos (300-1100 nm), $\alpha_{\text {base }}$ and $\alpha_{\text {top }}$, from 8 to 26 June 2013, was computed using Base Met and Top Met stations. Only shortwave flux measured at SZAs $<70^{\circ}$ (Stroeve et al., 2005) was used to minimize the cosine response error inherent to the pyranometers (uncertainty increases by $\pm 5 \%$ for SZAs $>70^{\circ}$; Onset Computer Corp. 2010). Expected accuracy of $\alpha_{\text {base }}$ and $\alpha_{\text {top }}$ is $\pm 10 \%$ based on the intrinsic accuracy and cosine response error of the pyranometers. Although surface roughness effects on mea- 


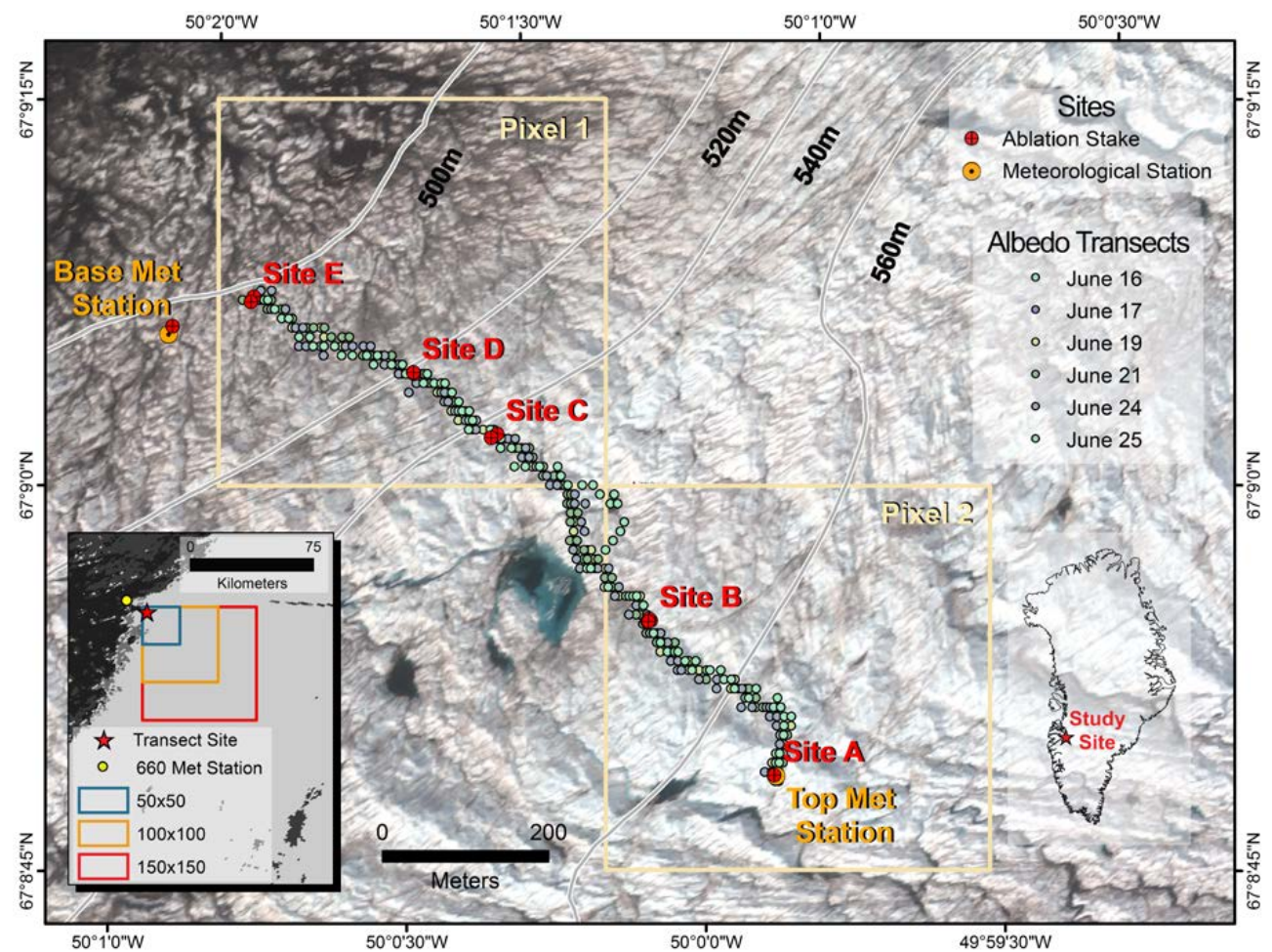

Figure 1. 23 June 2013 WorldView-2 true color image (bands 5, 3, and 2 RGB) of the study site with elevation contours (m), MODIS pixel extents (yellow boxes), and location of the six albedo transects, ablation stake, and meteorological station sites. Location of three MODIS spatial extent regions overlaid on a 31 May 2013 MOD10A1 image (black box inset).

sured surface albedos (e.g., Lhermitte et al., 2014) were not quantified here, analyses of $\alpha_{\text {top }}$ measurements suggest that they were compromised by these effects, and thus $\alpha_{\text {base }}$ alone is used for most analyses. See Appendix C for details on surface installation conditions and tilt uncertainty estimates.

\subsection{MODIS albedo data}

Daily MODIS broadband albedos $(300-3000 \mathrm{~nm})$ were acquired from the MOD10A1 product (Version 005) from NASA's Terra satellite (Hall et al., 2006; Klein and Stroeve, 2002). High-quality flagged MOD10A1 albedo data (periods of high SZA and cloudiness were excluded; Schaaf et al., 2011) from 31 May to 30 August 2012 and 2013 (when SZAs are minimized; e.g., Box et al., 2012) were used in two analyses. First, MOD10A1 albedos for pixels overlapping with our transect site (Fig. 1), hereafter $\alpha_{\text {MOD Pixel } 1}$ and $\alpha_{\text {MOD Pixel 2, were compared with observations as described }}$ below. Second, distributions of MOD10A1 albedo were examined at three spatial extents as described in Sect. 3.5.

Broadband $\alpha_{\text {MOD Pixel } 1}$ and $\alpha_{\text {MOD Pixel } 2}$ were compared with $\alpha_{\mathrm{ASD}}$ and $\alpha_{\text {base }}$. Direct comparison of $\alpha_{\mathrm{ASD}}, \alpha_{\text {base }}$, and $\alpha_{\mathrm{MOD}}$ absolute values are not possible due to different wavelength ranges, and $\alpha_{\mathrm{MOD}}$ is expected to have lower values than the other two data sets. However, relative comparisons of spatial and temporal patterns are reasonable, be- cause the $\alpha_{\mathrm{MOD}}$ is dominated by the ASD visible and nearinfrared (i.e., $325-1075 \mathrm{~nm}$ ) wavelengths. In a standard topof-atmosphere solar irradiance reference spectrum, the 325$1075 \mathrm{~nm}$ range comprises $81 \%$ of the total irradiance in the $300-3000 \mathrm{~nm}$ range. The dominance of reflectance in the ASD visible and near-infrared wavelengths in determining broadband albedos means that $\alpha_{\mathrm{MOD}}$ can be used qualitatively to provide spatiotemporal context. High-quality broadband (325-1075 nm) $\alpha_{\mathrm{ASD}}$ data within pixels 1 and 2, here-

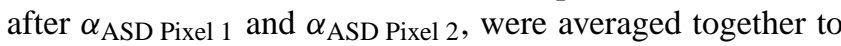
indirectly validate $\alpha_{\text {MOD Pixel } 1}$ and $\alpha_{\text {MOD Pixel } 2}$ data and to facilitate comparison between in situ and remotely sensed observations. While absolute values will differ between the data sets, and issues of MODIS pixel (px) separability may exist due to off-nadir footprint effects (Dozier et al., 2008), the difference should not change spatial and temporal patterns.

\subsection{Ablation and albedo at dominant surface types}

Surface melting between 8 and 26 June was estimated using ablation stakes installed at the Base Met Station, hereafter $M_{\text {base}}$, and at five sites across the albedo transect, hereafter

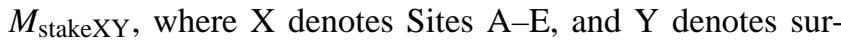
face type - clean/white ice (W), dirty ice (D), or shallow 5$10 \mathrm{~cm}$ deep streams (S) (Fig. 1). Bamboo poles were used as 
stakes (Hubbard and Glasser, 2005), and ablation rates were recorded every 1-3 days by measuring the distance between the bamboo pole top and ice sheet surface at centimeter-scale resolution.

$\alpha_{\text {ASD }}$ spectra were made within $30 \mathrm{~m}$ of ablation stakes to identify representative surface type albedos. With the exception of Site D, all sites were relatively homogenous. At Site D, the two surface types could be classified into distinct groupings: clean and dirty ice. Albedos of clean ice at Sites A-C and E, hereafter $\alpha_{\text {ASD_AW, }} \alpha_{\text {ASD BW, }} \alpha_{\text {ASD CW, and }}$ $\alpha_{\text {ASD_EW }}$, were estimated by averaging broadband $\alpha_{\text {ASD }}$ observations made within $30 \mathrm{~m}$ of stakes for each transect date. At Site D, albedos of clean and dirty ice, hereafter $\alpha_{\text {ASD_DW }}$ and $\alpha_{\mathrm{ASD}} \mathrm{DD}$, were estimated from the histograms of $\alpha_{\mathrm{ASD}}$ observations made within $30 \mathrm{~m}$ of stakes for each transect date. At the $M_{\text {base }}$ stake, no spectral $\alpha_{\text {ASD }}$ observations were made. Instead, $\alpha_{\text {ASD_DD }}$ is assumed to be representative of albedos at the Base Met Station, hereafter $\alpha_{\text {MET_base. }}$ Stream albedo, hereafter $\alpha_{\text {stream }}$, was determined from occasional $\alpha_{\text {ASD }}$ measurements at various shallow surface streams between 13 and 25 June. Cryoconite hole albedo, hereafter $\alpha_{\text {cryo, }}$, was parameterized using published values (from Bøggild et al., 2010) of broadband albedos averaged together for damp cryoconite material and cryoconite basin surface types under clear-sky and overcast conditions.

\subsection{Melt season albedo distributions}

Two types of melt season albedo distributions were constructed: (1) computed distributions based on broadband $\alpha_{\text {ASD }}$ for distinct surfaces and fractional surface coverage area from Chandler et al. (2015) and (2) observed MODISderived distributions.

The computed distributions were constructed by assuming that the albedo distribution for each distinct surface is represented by a normal distribution $N(\bar{x}, s)$, with $\bar{x}=\overline{\alpha_{\mathrm{ASD}}}$ representing surface type and standard deviation (estimated from ASD measurements), $s$, different for each surface type. Four distributions were constructed: clean ice $\mathrm{N}(0.56,0.07)$, dirty ice $\mathrm{N}(0.19,0.05)$, shallow streams $\mathrm{N}(0.23,0.09)$, and cryoconite holes $\mathrm{N}(0.10,0.05)$. Relative surface coverage of these four dominant surface types was derived at five distinct time periods (1, 19 June, 18, 28 July, and 5 August) over the 2012 melt season from Chandler et al. (2015; see Fig. 6a-g) to represent transient ice surface conditions, classified here as "early summer ice", "dirty ice exposure", "melt", "darkening ice", and "late summer ice", respectively (Table 3). A composite distribution for each distinct time step was calculated as the weighted mean of surface type distributions, where the weights were determined by their relative surface coverage area. Since Chandler et al. (2015) data are from 2012, results were not directly comparable with 2013 MOD10A1 data but should capture melt season evolution.

To compare with the computed distributions, high-quality 2012 and 2013 MOD10A1 data were used to construct ob- served albedo distributions at three spatial extents $(50 \times 50$, $100 \times 100$, and $150 \times 150$ pixel extents; Fig. 1$)$. The spatial resolution of the original MOD10A1 data is $463 \mathrm{~m}$ at nadir (exact resolution varies with overpass time), corresponding to study areas of $23.2,46.3$, and $69.5 \mathrm{~km}^{2}$ for the three spatial extents. Using a kernel smoothing density estimator, the average probability density distribution was computed at 0.01 albedo bin widths (range from 0.05 to 1 ). The seasonal average albedo distribution was calculated at the three spatial extents, and 5-day average albedo distributions and spatial averages were calculated for the $100 \times 100$ pixel scale for 2012 and 2013 MOD10A1 data.

\subsection{Identification of snowfall events}

To identify possible snowfall events in our study area and MODIS spatial extents, hourly precipitation and air temperature measurements collected by a meteorological station, hereafter 660 Met Station, installed near the ice sheet edge at the proglacial and ice sheet margin interface (Fig. 1), were examined. Near-surface air temperature measurements from the shorter Base Met Station time series (available from 8 to 26 June 2013) were also examined to estimate temperature differences between the proglacial and ice surfaces. Tundra near-surface air temperature $<1^{\circ} \mathrm{C}$ and precipitation $>0 \mathrm{~m}$ were used as criteria to identify dates of likely snowfall events. To validate that solid precipitation fell, NASA's WorldViewer (https://earthdata.nasa.gov/labs/ worldview/) was utilized to browse daily MODIS reflectance imagery (bands 7-2-1 and 3-6-7) to identify textural and brightness changes related to precipitation events.

\subsection{Computation of relative melt rates}

To examine seasonal changes in MODIS albedos, and estimate the importance of distinct surface types, relative surface melt rates were computed using the net shortwave solar radiation equation, observed values of incoming solar radiation from the Base Met Station on 16, 19, and 25 June, and broadband albedo values for computed and observed distribution methods. The observed incoming solar radiation values were averaged together and kept constant in the relative melt rate calculations to isolate the effects of albedo changes on melt. Net solar radiation $\left(E_{\mathrm{R}}\right)$ varies as a function of incoming solar radiation $\left(E_{\mathrm{S}}^{\downarrow}\right)$ and albedo $\left(\alpha_{s}\right)$, where units of energy are represented as $\mathrm{W} \mathrm{m}^{-2}$ :

$E_{\mathrm{R}}=E_{\mathrm{S}}^{\downarrow}\left(1-\alpha_{\mathrm{s}}\right)$.

Melt rate, defined as the heat needed to melt snow/ice when near-surface temperatures are $\geq 0{ }^{\circ} \mathrm{C}$, was computed in units of $\mathrm{m} \mathrm{s}^{-1}$ (Cuffey and Patterson, 2010):

$M=E_{\mathrm{R}}\left(L_{\mathrm{f}} \cdot \rho_{\mathrm{w}}\right)^{-1}$.

where $L_{\mathrm{f}}$ is latent heat of fusion $\left(3.34 \times 10^{5} \mathrm{~J} \mathrm{~kg}^{-1}\right)$ and $\rho_{\mathrm{W}}$ is density of water $\left(1000 \mathrm{~kg} \mathrm{~m}^{-3}\right)$. Since the meteorologi- 

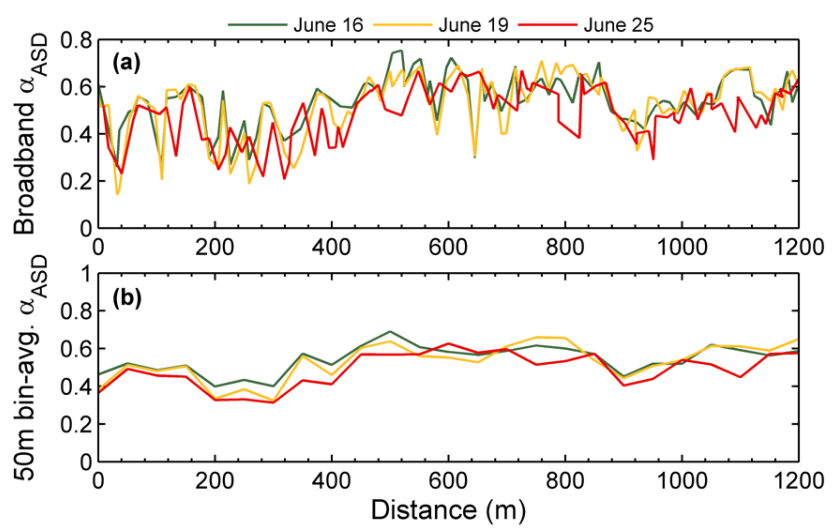

Figure 2. High-quality broadband $\alpha_{\mathrm{ASD}}$ observations on 16, 19, and 25 June (a) and broadband $\alpha_{\text {ASD }}$ averaged in $50 \mathrm{~m}$ bins (b) along the length of the transect starting near Site E $(0 \mathrm{~m})$ and ending near Site A (1200 m).

cal station data sets lack surface energy balance terms (i.e., net long-wave radiation, sensible and latent heat fluxes) required to compute the entire energy budget, calculating absolute melt rates was not possible. Instead, the percent difference in estimated melt rates was computed for each distribution relative to the early melt season ablation rates (mean of $4.40 \times 10^{-7} \mathrm{~m} \mathrm{~s}^{-1}$ for "early summer ice" computed distribution; mean of $2.70 \times 10^{-7} \mathrm{~m} \mathrm{~s}^{-1}$ for 31 May-4 June observed MODIS distribution).

\section{Results}

\subsection{Spatiotemporal patterns in ablation area transect albedo}

Spatial variability of broadband $\alpha_{\mathrm{ASD}}$ along the transect follows a consistent pattern on all three dates, averaging low values $(0.50 \pm 0.04)$ the first $\sim 300 \mathrm{~m}$, followed by increased albedo, reaching a plateau of $0.64 \pm 0.07$ at $\sim 600 \mathrm{~m}$, and remaining nearly constant with the exception of a dip to $0.44 \pm 0.02$ at $\sim 900 \mathrm{~m}$ (Fig. 2a). While discrete $\alpha_{\text {ASD }}$ observations often differ from the nearest observation made at another transect time due to slight day-to-day changes in the sample location (Fig. 2a), data averaged in $50 \mathrm{~m}$ bins covary spatially along the transect gradient (Fig. 2b). The spatial variability of broadband $\alpha_{\mathrm{ASD}}$ is considerable and varies between a minimum of 0.14 (19 June) and a maximum of 0.75 (16 June; Table 1 ). The high variability in discrete $\alpha_{\text {ASD }}$ values over short distances (Fig. 2a) is indicative of the heterogeneous surface that characterizes the field site and surrounding ablation area not necessarily captured in $\alpha_{\text {base }}$ observations.

Temporal variability in daily average $\alpha_{\text {base }}$ follows a nonlinear decline from 8 to 26 June 2013 starting at 0.49 and ending at 0.34 (Fig. 3). An increase in $\alpha_{\text {base }}$ of 0.11 be-

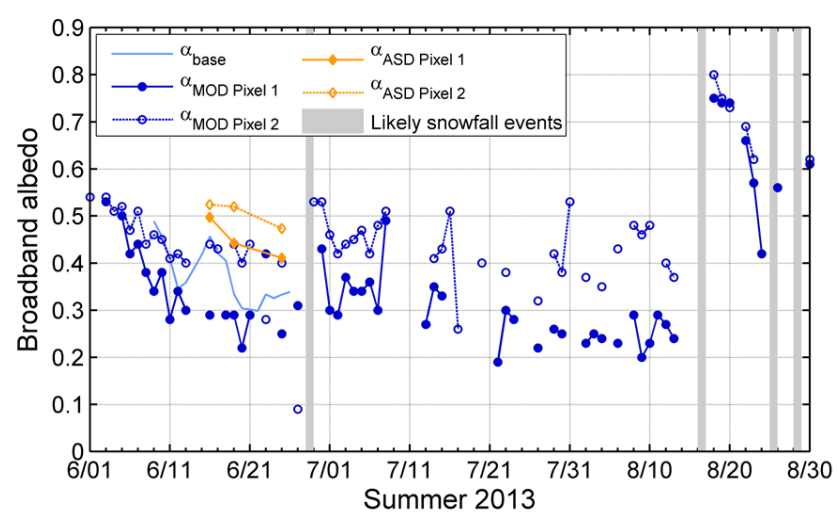

Figure 3. High-quality daily average broadband $\alpha_{\text {MOD Pixel } 1}$ and $\alpha_{\text {MOD Pixel 2 }}, \alpha_{\text {base }}$ (for SZA $<70^{\circ}$ ), and $\alpha_{\text {MOD Pixel } 1}$ and $\alpha_{\text {MOD Pixel } 2}$ time series for the 2013 melt season. $\alpha_{\text {ASD Pixel } 1}$ and $\alpha_{\text {ASD Pixel }} 2$ pixel-averaged values correspond to high-quality ASD transect dates 16, 19, and 25 June. Grey shaded regions show likely snowfall events.

tween 12 and 16 June might be related to tilt errors, which influenced what part of the increasingly heterogeneous surface the instruments were monitoring. Indeed, the net lowering of $\alpha_{\text {base }}$ by 0.15 between 8 and 26 June is consistent with $\alpha_{\text {MOD Pixel } 1}$ and $\alpha_{\text {MOD Pixel } 2}$ observations from June to mid-August. $\alpha_{\text {MOD Pixel } 1}$ and $\alpha_{\text {MOD Pixel } 2}$ drop from values slightly above 0.5 in June to 0.24 and 0.37 , respectively, around mid-August. Between these dates, sudden increases in albedo could be caused by occasional snowfall events (Fig. 3). Potential snowfall events were identified as time periods with 660 Met Station temperatures $<1{ }^{\circ} \mathrm{C}$ that coincided with precipitation events. The $1{ }^{\circ} \mathrm{C}$ offset is motivated by the environmental lapse rate. This suggests that the higher elevation of the ice sheet would be at freezing, and precipitate as snow. By using this method to identify snowfall events, a brief event likely occurred on 28-29 June (Fig. 3) raising MOD10A1 albedos from 0.31 to 0.53 between 27 and 30 June. July MOD10A1 albedos exhibited some temporal variability but were generally lower at the end than the start of the month. It is unclear if they were triggered by snowfall events. While precipitation events occurred several times on the tundra in July, it is unknown whether these events extended to the ice sheet and whether temperatures were sufficiently cold to trigger snow rather than rain. August MOD10A1 albedos increased from early to late in the month with a snowfall event on $\sim 18$ August, triggering large increases in albedos to values above 0.75 . High-quality daily average broadband $\alpha_{\text {MOD Pixel } 1}$ and $\alpha_{\text {MOD Pixel } 2}$ data do not exhibit the slight increase in $\alpha_{\text {base }}$ at the end of June (0.04 from 22 to 26 June), which may be reflected by differences in footprint sizes, a lower $\alpha_{\text {ASD }}$ sampling frequency, and $\alpha_{\text {base }}$ tilt errors. Instead, $\alpha_{\text {ASD Pixel } 1}$ and $\alpha_{\text {ASD Pixel } 2}$ data exhibit a steady decline over the month of June, while $\alpha_{\text {MOD Pixel } 1}$ and $\alpha_{\text {MOD Pixel } 2}$ data remain relatively constant over the same time period. Ab- 
Table 1. Descriptive statistics for high-quality albedo transects. SZA and CC listed for Base Met Station only. "brd" is used to abbreviate broadband.

\begin{tabular}{|c|c|c|c|c|c|c|c|c|c|c|c|c|c|}
\hline $\begin{array}{l}\text { Transect } \\
\text { date }\end{array}$ & $\begin{array}{l}\text { Start } \\
\text { time }\end{array}$ & $\begin{array}{l}\text { End } \\
\text { time }\end{array}$ & $\begin{array}{l}\text { Min brd } \\
\alpha_{\mathrm{ASD}}\end{array}$ & $\begin{array}{l}\text { Max brd } \\
\alpha_{\mathrm{ASD}}\end{array}$ & $\begin{array}{l}\text { Mean brd } \\
\alpha_{\mathrm{ASD}}\end{array}$ & $\begin{array}{l}\text { Daily average } \\
\alpha_{\text {base }}\end{array}$ & $\begin{array}{l}\text { Daily average } \\
\alpha_{\text {top }}\end{array}$ & $\begin{array}{l}\text { Min SZA } \\
\left({ }^{\circ}\right)\end{array}$ & $\begin{array}{l}\text { Max SZA } \\
\left({ }^{\circ}\right)\end{array}$ & $\begin{array}{l}\text { Mean SZA } \\
\left({ }^{\circ}\right)\end{array}$ & $\begin{array}{l}\text { Min } \\
\text { CC }\end{array}$ & $\begin{array}{l}\text { Max } \\
\text { CC }\end{array}$ & $\begin{array}{l}\text { Mean } \\
\text { CC }\end{array}$ \\
\hline 16 June & $10: 32: 33$ & $11: 53: 57$ & 0.260 & 0.754 & 0.550 & 0.404 & 0.636 & 45.615 & 50.454 & 47.828 & 0.135 & 0.176 & 0.157 \\
\hline 19 June & $10: 39: 30$ & $11: 35: 59$ & 0.141 & 0.730 & 0.532 & 0.316 & 0.541 & 46.449 & 49.925 & 48.093 & 0.045 & 0.084 & 0.065 \\
\hline 25 June & $10: 20: 29$ & 11:11:00 & 0.210 & 0.670 & 0.490 & 0.333 & 0.525 & 47.963 & 51.525 & 49.677 & 0.119 & 0.138 & 0.125 \\
\hline
\end{tabular}

Table 2. Average broadband $\alpha_{\text {ASD }}$ within a $30 \mathrm{~m}$ radius of ablation stake sites and classified by surface type. The number within the parenthesis denotes the sample size.

\begin{tabular}{lll}
\hline Ablation stake sites & Clean surfaces & Dirty surfaces \\
\hline Site A & $0.641(4)$ & - \\
Site B & $0.540(4)$ & - \\
Site C & $0.591(7)$ & - \\
Site D & $0.530(4)$ & $0.243(2)$ \\
Site E & $0.555(5)$ & - \\
\hline
\end{tabular}

solute magnitudes among the three ground- and satellitederived albedo products diverge due to sensor, wavelength range, and spatial resolution differences. However, all products have higher albedo values at the beginning as compared with the end of the month of June, prior to the 28-29 June snowfall event.

Albedos of dirty and clean ice surfaces are distinctly different for each ablation stake site (Table 2). Broadband $\alpha_{\mathrm{ASD}}$ spectra made within $30 \mathrm{~m}$ of ablation stakes were individually assessed to classify each surface type into two distinct groupings: clean and dirty ice. Only Site D had both dirty and clean ice surfaces. Manual inspection of individual spectra at Site D confirm that samples with $\alpha_{\mathrm{ASD}}<0.4$ are qualitatively similar to typical spectra for wet or debris-rich ice, as shown in Pope and Reese (2014), and distinctly different from values of $\alpha_{\mathrm{ASD}}>0.4$.

\subsection{Melt season albedo distributions}

\subsubsection{3 computed and observed distributions}

Computed albedo frequencies using typical albedo values for four distinct surface types (Table 3 and Sect. 3.5) and changing area fractions of these surfaces identified at a nearby site by Chandler et al. (2015) reveal a bimodal distribution as the melt season progresses (Fig. 4). The relative strength of the first and secondary modes change as the fractional area of darker surfaces expands from "dirty ice exposure" to "melt" distributions and onwards. At the start of the melt season, the abundance of lighter surfaces coincides with a higher probability of high broadband $\alpha_{\text {ASD }}$ values. Here, snow and clean ice surfaces dominate and gradually degrade, exposing the impurity-rich surface underneath. As darker surfaces progressively populate the ablation area with the onset of the

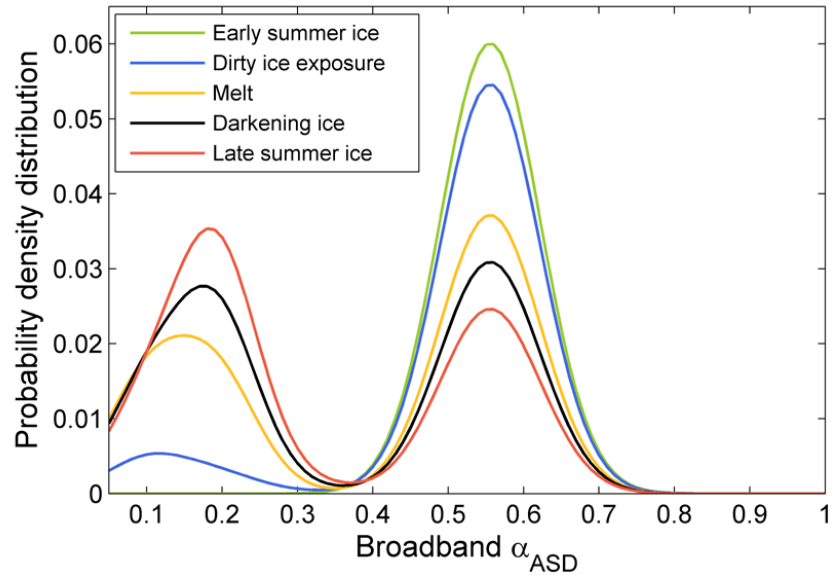

Figure 4. Computed albedo distribution for a nearby site of Chandler et al. (2015) simulated across the melt season based on observed broadband $\alpha_{\text {ASD }}$ values for dominant surface types, weighted by their relative surface area coverage. Each surface type is assumed to follow a normal distribution. Computed albedo distributions represent the sum of each surface type's probability distribution function.

melt season, computed albedo distributions predict a concomitant higher probability of lower albedos. Thus, there is an apparent dichotomy between darker and lighter surfaces "competing" to control the overall albedo distribution of the ablation area. A transition towards a distribution biased towards lower albedo values is due to darker surfaces shifting the overall distribution and is consistent with high-quality broadband $\alpha_{\text {ASD }}$ distributions (Fig. 5). Relative melt rates increase sharply (by $25.7 \%$ ) from "dirty ice exposure" to "melt", coinciding with a strengthening of the second, lower mode in the computed albedo distribution (Table 4). Once the secondary mode is established, a smaller increase in melt rates occurred as the mode strengthens from "melt" to "darkening ice" and finally to "late summer ice" (6.7 and 9.1\%, respectively).

Observed 2013 MOD10A1 albedo distributions at three spatial extents (Fig. 6) reveal that the bimodal distributions (cf. Fig. 4) are manifested in reality at the $100 \times 100$ MODIS px extent (i.e., $46.3 \mathrm{~km}^{2}$ ). While the spatial extent of the MOD10A1 sample influences the seasonal average albedo distribution, two distinct surface types - dark and light surfaces - dominate the seasonal signal (Fig. 6). At the smallest spatial extent $\left(50 \times 50 \mathrm{px}-\right.$ i.e., $\left.23.2 \mathrm{~km}^{2}\right)$, lower albe- 
Table 3. Seasonal evolution (\%) of four surface types at five distinct time steps approximated from Chandler et al. (2015).

\begin{tabular}{llcccc}
\hline Time steps & Classified names & Clean ice & Dirty ice & Streams & Cryoconite holes \\
\hline 1 June & Early summer ice & 100 & 0 & 0 & 0 \\
19 June & Dirty ice exposure & 90 & 3 & 1 & 6 \\
18 July & Melt & 60 & 20 & 1 & 19 \\
28 July & Darkening ice & 50 & 30 & 3 & 17 \\
5 August & Late summer ice & 40 & 40 & 6 & 14 \\
\hline
\end{tabular}

Table 4. Percent difference in melt rate estimates for different albedo probability density functions and averaged incoming solar radiation conditions at Base Met Station from 16, 19, and 25 June relative to "early summer ice" (1 June) distribution.

\begin{tabular}{lll}
\hline Time steps & Classified names & $\begin{array}{l}\text { Melt rate percent } \\
\text { difference }(\%)\end{array}$ \\
\hline 19 June & Dirty ice exposure & 8.28 \\
18 July & Melt & 34.01 \\
28 July & Darkening ice & 40.73 \\
5 August & Late summer ice & 49.83 \\
\hline
\end{tabular}

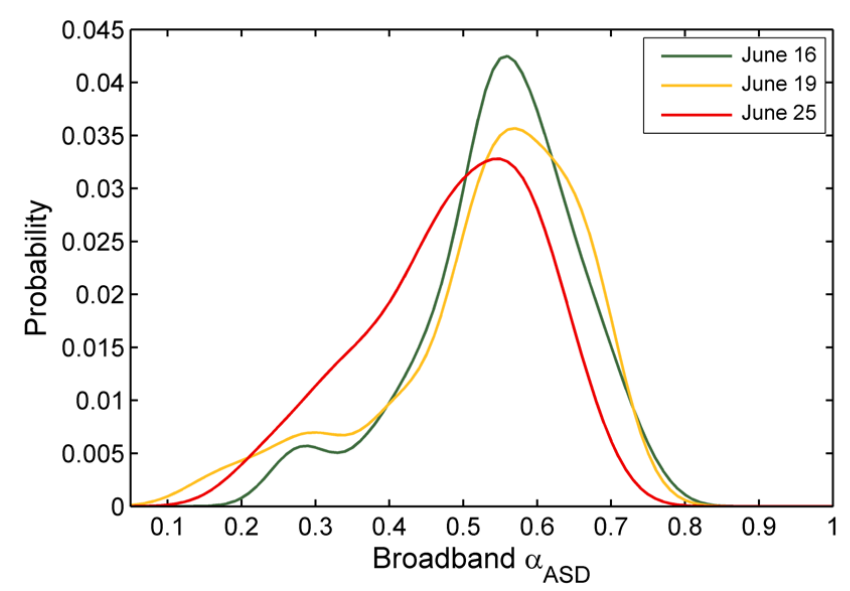

Figure 5. Observed distributions of high-quality broadband $\alpha_{\mathrm{ASD}}$ transects on 16,19 , and 25 June.

dos from darker surfaces of the lower ablation area control the density distribution, while at the largest spatial extent $\left(150 \times 150 \mathrm{px}-\right.$ i.e., $\left.69.5 \mathrm{~km}^{2}\right)$ the probability distribution is primarily influenced by higher albedos from lighter surfaces (e.g., snow) of the upper ablation area. The central tendencies of each mode are $\sim 0.46$ and $\sim 0.72$, which are much larger than in the computed distributions $(\sim 0.18$ and $\sim 0.56$; cf. Fig. 4).

The bimodal distribution identified in the observed $100 \times 100$ px MODIS albedo distribution in 2013 (Fig. 6) is the result of snow and ice surfaces characterizing the two peaks, as each mode centers around typical values of snow and clean ice, respectively. As such, the observed MODIS bimodal distribution is associated with a transition from ice

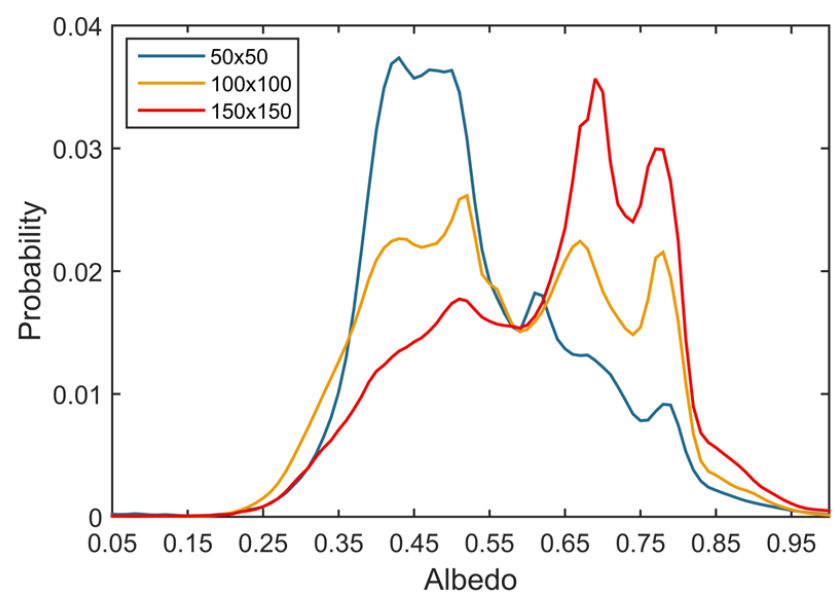

Figure 6. MOD10A1 2013 seasonal average albedo probability density distributions at three spatial extents: $50 \times 50$ MODIS pixels $(\mathrm{px}), 100 \times 100 \mathrm{px}$, and $150 \times 150 \mathrm{px}$. The bimodal distribution seen at the $100 \times 100 \mathrm{px}\left(46.3 \mathrm{~km}^{2}\right)$ spatial extent is likely the result of almost equal area of snow and ice facies characterizing the two peaks. In contrast, the right and left skew distributions of $50 \times 50 \mathrm{px}$ and $150 \times 150 \mathrm{px}$ illustrate the dominance of ice and snow surfaces, respectively.

to snow, rather than a change from clean to dirty ice, which caused the two modes in the computed distribution (Fig. 4). Indeed, analysis of 2013 meteorological observations reveal that short term snowfall events that fell on top of the underlying ice can result in variations in ablation area albedos (Fig. 3). In 2013, the bimodal distribution at the $100 \times 100 \mathrm{px}$ spatial extent is likely the result of snow deposition or redistribution of blowing snow (e.g., Gorter et al., 2014; Lenaerts et al., 2014) on top of the ice surface (Fig. 6).

MOD10A1 albedo at the $100 \times 100 \mathrm{px}$ (i.e., $46.3 \mathrm{~km}^{2}$ ) spatial extent transitions from a unimodal distribution with high albedo values at the start of the melt season (31 May-4 June) to a bimodal-like distribution with intermediate albedo values at mid-melt season (20-24 June) and shifts abruptly to a new, unimodal distribution with low albedo values at peak melt season (30 July-3 August; Fig. 7). By assuming an unchanged radiation budget, the relative impact of albedo distribution changes on melt rates was quantified. The abrupt shift from a lighter-dominated (high albedo) to darker-dominated (low albedo) surface corresponds to an observed melt rate 


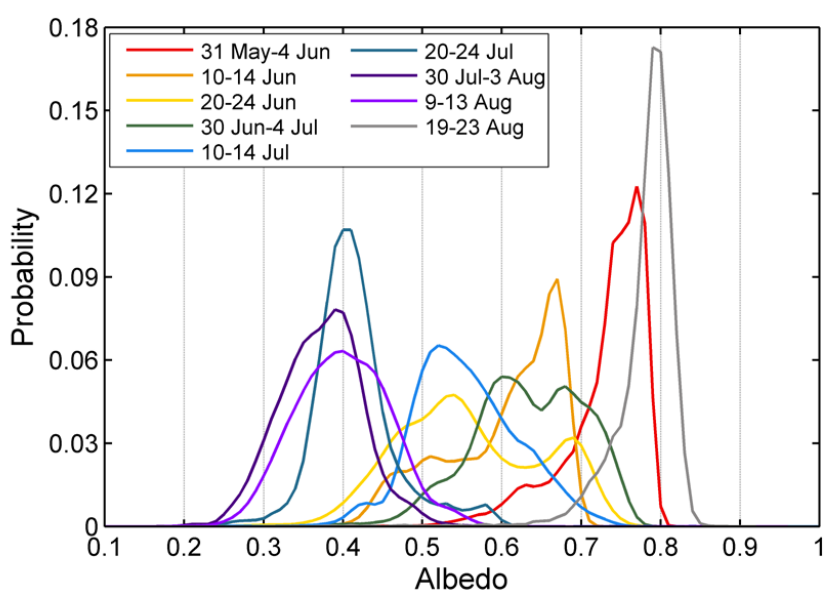

Figure 7. $100 \times 100$ px 5-day averages over the 2013 melt season. Every other 5-day average line is plotted.

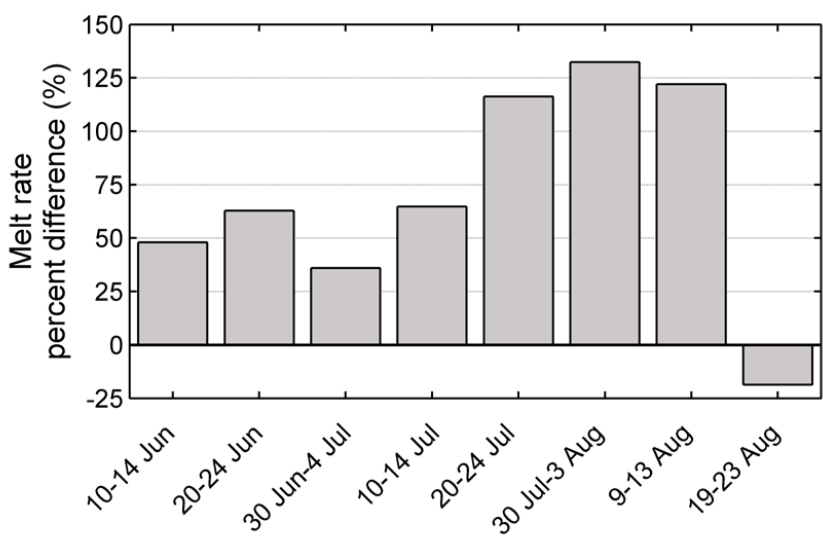

Figure 8. Percent difference in melt rate estimates for $100 \times 100 \mathrm{px}$ 5-day average albedo distributions for the 2013 melt season relative to 31 May-4 June 5-day average albedo distribution. Melt rates are calculated with identical radiation budget conditions to isolate the effect of albedo distribution changes.

percent difference increase of $51.5 \%$ between the 10-14 July and 20-24 July 5-day average albedo distributions (Fig. 8). Before and after this shift, melt rates changed much less from each 5-day average, ranging between $\sim 10$ and $30 \%$, with the exception of the dramatic drop of $103.3 \%$ when the melt season ends in late August.

The bimodality seen in the 30 June-4 July 5 -day average distribution (Fig. 7) coincides with a brief period of higher MODIS albedo values $(\sim 0.6-0.7)$, indicative of snow. Identification of a snowfall event on 28-29 June 2013 (Fig. 3) confirms the source of the bimodal distribution observed in the 30 June-4 July 5-day average (Fig. 7), corresponding to a brief "jump" in the probability density distribution to higher albedos.

\subsubsection{Differences between 2012 and 2013 observed albedo distributions}

While the 2013 MODIS albedo bimodal distribution shown in Figs. 6 and 7 are a result of snow and ice albedos, analysis of MODIS 2012 data reveals a more complex, multimodal albedo distribution (Fig. 9). These distributions cannot be explained by the presence or absence of snow and ice alone. The 2012 MODIS observations are characterized by generally lower albedos, with six out of nine 5-day average albedo distributions ranging mostly between 0.2 and 0.5 compared to three out of nine 5-day average albedo distributions in 2013 (cf. Fig. 7 and 10). These low albedos are confirmed by the average seasonal MODIS 2012 albedo distributions, where a higher probability of albedos are centered on $\sim 0.35$, compared to two peaks at $\sim 0.45$ and $\sim 0.7$, in 2013 at the $100 \times 100$ px spatial extent (cf. Figs. 6 and 9). The higher probability of these very low albedos observed in 2012 are likely due to dust, sediment, and impurity-rich ice in the so-called 'dark-band' region (Wientjes and Oerlemans, 2010). The identification of this dark zone feature is presented in Sect. 4.2.3.

\subsubsection{2 vs. 2013 spatial albedo maps}

The presence of the dark-band region is confirmed by the diagonal band of very low albedos $(<\sim 0.35)$ in the 2012 MODIS seasonal average at the $100 \times 100 \mathrm{px}$ extent (Fig. 11). However, the presence of the dark-band region is not visible in 2013 when albedo gradually increases from west to east (Fig. 12). The lack of the dark zone feature in 2013 is likely due to snow covering the dark band for most of the season. Overall, 2012 exhibits substantially lower ablation area albedos (Fig. 10), while 2013 reveals higher ablation area albedos in the MODIS spatial averages (Fig. 7). The large inter- and intra-annual variability in MODIS ablation area albedos may be indicative of the large spatial variability in surface types that characterize the lower elevations of the ablation area. Alternatively, a larger distribution in cryoconite hole coverage may have also contributed to low albedos $(\sim 0.25)$ observed in the 2012 MODIS seasonal averages (Fig. 9).

\subsection{Relative melt rates}

Observed ablation rates, derived from stake readings, are typically higher for dark surfaces (dirty ice and streams) than light surfaces (clean ice; Fig. 13). Clean ice surfaces have higher broadband $\alpha_{\text {ASD }}$ values (mean of 0.57 ), corresponding to lower average ablation rates $\left(5.38 \times 10^{-7} \mathrm{~m} \mathrm{~s}^{-1}\right)$. In contrast, dirty ice and stream surfaces have lower mean broadband $\alpha_{\text {ASD }}$ values (0.24), corresponding to higher average ablation rates $\left(6.75 \times 10^{-7} \mathrm{~m} \mathrm{~s}^{-1}\right)$. The observed mean difference between light and dark surface ablation rates is $1.37 \times 10^{-7} \mathrm{~m} \mathrm{~s}^{-1}$. Melt rate calculations (Eqs. 1 and 2) re- 


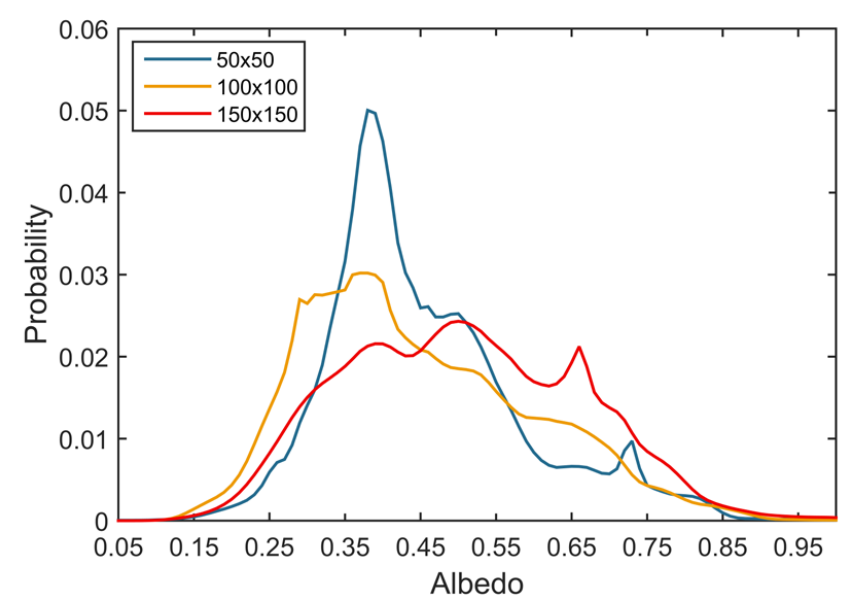

Figure 9. MODIS 2012 seasonal average albedo probability density distributions at three spatial extents. The MODIS 2012 seasonal average albedo probabilities for the $100 \times 100 \mathrm{px}$ and $150 \times 150 \mathrm{px}$ reveal a high probability of low albedo values $(0.2-0.3)$. This is likely influenced by the expansion of the "dark-band" region in these spatial extents.

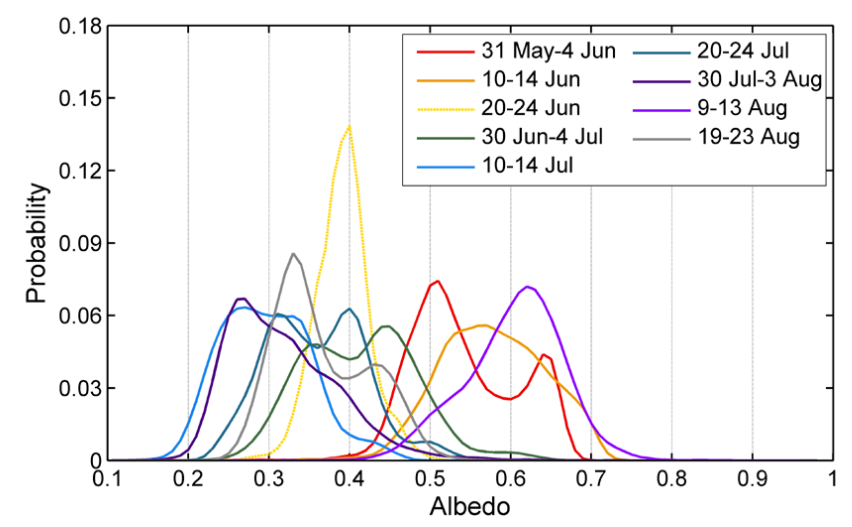

Figure 10. MODIS $100 \times 100 \mathrm{px}$ spatial extent 5-day average albedo distributions for the 2012 melt season. Note that the 20-24 June 5-day average (yellow stippled line) is most likely erroneous due to an outlier in the MODIS data on 21-22 June 2012.

sulted in a lower average ablation rate for clean ice surfaces $\left(4.24 \times 10^{-7} \mathrm{~m} \mathrm{~s}^{-1}\right)$ and a higher average ablation rate for dark ice surfaces $\left(7.56 \times 10^{-7} \mathrm{~m} \mathrm{~s}^{-1}\right)$, corresponding to a mean difference of $3.33 \times 10^{-7} \mathrm{~m} \mathrm{~s}^{-1}$. Differences between observed and calculated melt rates could be due to ablation stake measurement errors and simplification of calculations (e.g., no consideration of long-wave radiation or turbulent heat fluxes). Regardless, in both cases relative melt rates between light and dark surfaces are considerably different and thus, useful for investigating seasonal melt rate changes as described below.

The spread in observed clean ice broadband albedo values results in greater variability in observed ablation rate estimates (Fig. 13). In contrast, minimal broadband albedo variability is observed for dirty ice surfaces. Few dirty ice albedo

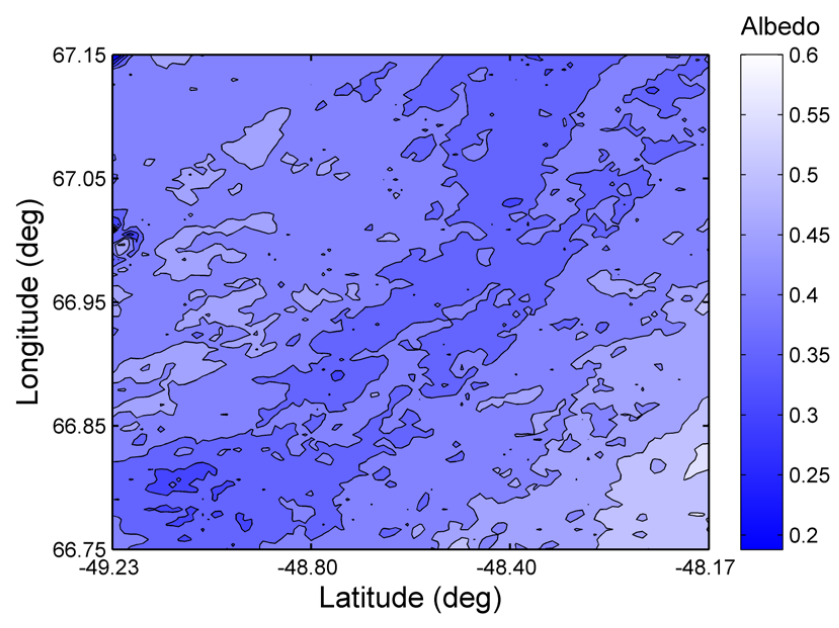

Figure 11. MODIS 2012 seasonal average for the $100 \times 100$ spatial extent. A region of dark ice, known as the "dark band", extends through our study area $(<\sim 0.35$, shown in bright blue colors).

measurements were sampled as compared to clean ice surfaces. Differences in observed ablation rates for streams are due to a lack of albedo measurements taken over these surfaces. While ablation rates were measured at several ablation stake stream sites, only occasional $\alpha_{\mathrm{ASD}}$ measurements were collected over these surfaces. Considerable spread in ablation rates for stream observations could be explained by varying stream depth (Legleiter et al., 2014). The depth of these streams determines the attenuation and scattering of radiant energy, thereby influencing the observed albedo measurements. Sensible heat flux from the stream water, not accounted for in radiative estimates, may also be a mechanism for increased melting.

\section{Discussion}

\subsection{The importance of surface types in observed and computed ablation area albedos}

GrIS ablation area albedos are strongly influenced by the presence or absence of impurity-rich debris on its surface. Clean ice and dust-covered, dirty ice have distinctly different albedos, resulting in a left-skewed albedo distribution in the middle and end of June (Fig. 5). This pattern is supported by computed and remotely sensed albedo distributions, revealing that a multi-modal distribution develops seasonally. A modest melt or snowfall event can trigger a sudden switch from a high to low albedo mode or vice versa, drastically changing ablation rates. These findings suggest that shifts in dominant surface type from snow to bare ice and clean ice to impurity-rich surfaces are important drivers in abruptly increasing seasonal ice sheet melt rates.

The first quality-controlled in situ ablation area albedo data set collected along a $1.25 \mathrm{~km}$ transect during 3 days 


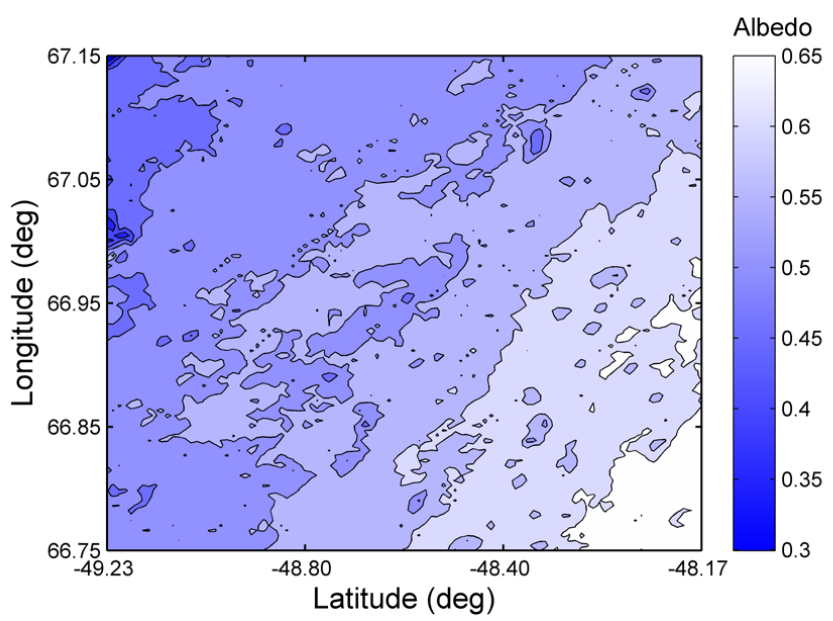

Figure 12. MODIS 2013 seasonal average for the $100 \times 100$ px spatial extent. Overall higher MODIS albedo values are observed in 2013 without a "dark-band" region surface expression.

in June 2013 is presented. Albedo data collected during in situ transect dates resemble an early summer ice surface classified in Chandler et al. (2015) and Knap and Oerlemans (1996; Fig. 4). Here, remaining snow cover and superimposed ice gradually melts, revealing underlying impurities and cryoconite holes. Visual assessment and continuous monitoring in the field revealed that the ice surface along the transect was snow-free from 8 to 26 June 2013. This period corresponds to a nonlinear decrease in albedos (Fig. 3). Accumulation of exposed below-surface impurities (Wientjes and Oerlemans, 2010), the gradual erosion of snow patches in local depressions on the ice surface (van den Broeke et al., 2011), as well as the activation and development of the hydrologic system and cryoconite hole coverage (Chandler et al., 2015) may mitigate the rate of change in ablation area albedos. Turbulent sensible heat fluxes from adjacent proglacial areas provide an additional explanation for the nonlinear decline in ground albedo measurements, serving to limit the melt-albedo feedback's influence (van den Broeke et al., 2011).

Under the assumptions that distinct surface types albedos follow a normal distribution, a bimodal probability distribution preferentially develops as ablation area albedo decreases rapidly over the melt season due to development of an efficient meltwater drainage system, increase in cryoconite hole coverage, and accumulation of debris-rich sediments (Fig. 4). An increase in debris-rich and stream surfaces over the melting season (Fig. 4) is likely responsible for the enhanced frequency of low albedo values identified in the observed $\alpha_{\text {ASD }}$ distribution from 16 to 25 June (Fig. 5). However, the observed changes at transect sites appear to be more gradual than for the MODIS data (Figs. 7 and 10). This may be due to a lack of snow cover influencing the local albedo distribution and a lower temporal sampling frequency. The lack of

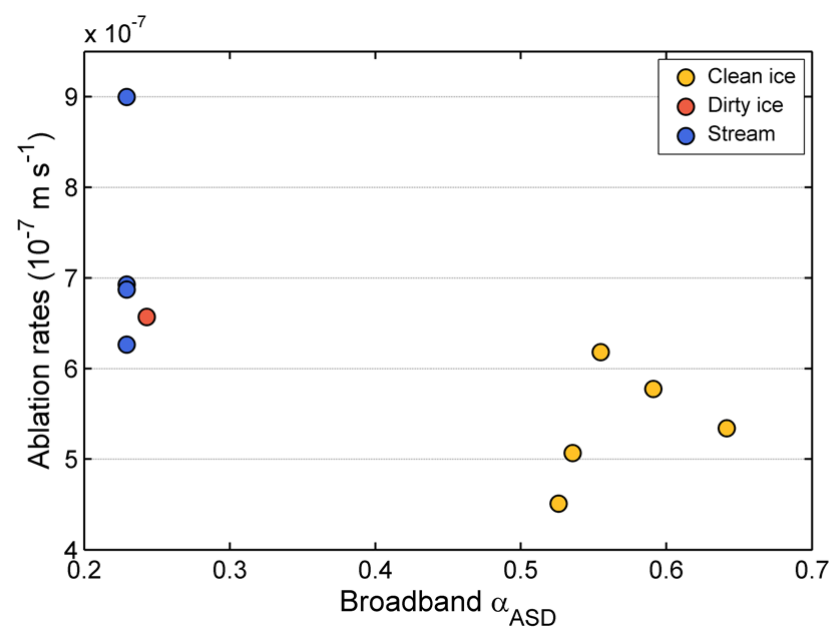

Figure 13. Observed ablation rates and broadband $\alpha_{\text {ASD }}$ for different ice surface types.

a pronounced secondary mode with lower albedo values in the observed left-skewed distributions (Fig. 5) compared to the modeled bimodal distribution (Fig. 4) may be related to different melt season conditions (2012 vs. 2013) and a corresponding range of surface types captured along the transect which undersamples dark surfaces (e.g., dirty ice and stream surfaces; Table 2). Chandler et al. (2015) surface types cover a wider range of surface types and, thus, albedos.

Compared to reality, the computed distribution (Fig. 4) probably overemphasizes each mode and does not account for darkening due to ice crystal growth over the melting season. The observed albedo distributions reveal abrupt and variable shifts in the seasonal albedo distribution (Figs. 7 and 10). At certain spatial extents, these albedo distributions transition from a high- to low-dominated mode (Fig. 6), enabling enhanced melt rates (Table 4 and Fig. 8). Alexander et al. (2014) also observed bimodal albedo distributions for Greenland's ablation area by analyzing MAR and MODIS products between 2000 and 2013. Alexander et al. (2014) attribute the dominant modes to the presence of snow and ice (and firn). This is in agreement with the analysis of the 2013 conditions but disagrees with 2012 conditions. This discrepancy could be due to the larger study area that includes areas unaffected by dust from deposition and outcropped ice layers and a 13-year averaging period suppressing outlier years like 2012 used in Alexander et al. (2014).

The 2013 bimodal albedo distributions (Fig. 7) shifts from higher to lower albedo modes in the melt season (Fig. 4) indicating that a switch in dominant surface type (i.e., from light to dark) during the melt season, and not solely grain size metamorphism, is largely responsible for lowering albedo in snow-free ablation areas. Furthermore, results from the MODIS data (Figs. 7 and 10) suggest that a transition from a light- to dark-dominated surface is abrupt rather than gradual, likely associated with the addition and removal of snow. 
The transition is more gradual in the left-skewed observed (Fig. 5) and computed albedo distributions (Fig. 4), likely reflecting changes in impurity content and different data set time sampling. Consistent with Chandler et al. (2015), the initial drop in MODIS ablation area albedos is likely due to both the transition from dry to wet and patchy snow surfaces. Successive lowering of albedos after snow melt is predominantly due to an increase ice crystal size (Box et al., 2012) and possibly also by expansion of darker surface area coverage (e.g., cryoconite holes, accumulation of impurities, and stream organization) and melting of dust-enriched ice layers. These distributions correspond to percent differences (e.g., 51.5\% between the 10-14 July and 20-24 July 5day averages) in melt rate estimates that are substantial over the melt season (Table 4 and Fig. 8) and highlight the importance of considering the albedo of ablation area surface types. The higher melt rates associated with darker surfaces (Fig. 13) may lead to lighter surfaces becoming topographically prominent. In theory, this should enhance sensible heat transfer to the lighter surfaces, increasing their ablation. Future studies should consider quantifying the effects of surface roughness on ablation area albedos (e.g., Warren et al., 1998; Zhuravleva and Kokhanovsky, 2011).

Recent studies have proposed scenarios of future atmospheric warming, in which excess deposition of lightabsorbing impurities (Dumont et al., 2014) and black carbon from increased forest fire frequency or incomplete fuel combustion (Keegan et al., 2014) will promote accumulation of impurities, contributing to amplified surface melting. If these findings are confirmed, these effects will likely be exacerbated in southwest Greenland's ablation area, where continued negative albedo trends (Stroeve et al., 2013) and increasingly warmer average summer temperatures (Keegan et al., 2014), in conjunction with bare ice, light-absorbing impurities, and cryoconite holes, are expected to dominate.

\subsection{Insights from 2012 and 2013 melt seasons' albedo distributions}

The spatial distribution of snow cover and background bare ice albedos is important for understanding temporal changes in 2012 and 2013 MODIS albedo distributions (Figs. 11 and 12). Compared to 2013, snow melt in 2012 was more pronounced and reached higher elevations (Tedesco et al., 2014), allowing the dark-band feature to be exposed, resulting in a lower seasonal albedo mode (Fig. 9).

The large albedo distribution changes from one MODIS 5-day average to another in 2012 (Fig. 10) is likely due to variability in meltwater ponding on the ice surface and perhaps deposition of wind-blown dust from tundra regions but not necessarily increases in melted-out debris from internal ice layers at such short timescales. However, exposure of dust and sediment-rich ice surfaces probably caused the high probability of considerably low 2012 MODIS albedo values relative to 2013. This is expected since it was identified as an extreme melt year with early onset snow melt (e.g., Nghiem et al., 2012; Tedesco et al., 2013; Figs. 9 and 10), while 2013 was a normal melt year in the 1979-2013 context (Tedesco et al., 2014). Given the coarse resolution of the MODIS pixel, it is likely that it averages out finer-scale details of distinct surface types (e.g., dirty ice and cryoconite hole surfaces) along the ice sheet edge. It is hypothesized that higher spatial resolution satellite imagery may be able to capture such regions closer to the ice sheet margin. We postulate that the area of these regions may grow in size over the melting season as demonstrated on local scales by Chandler et al. (2015) in situ observations.

The bimodal distribution observed in the 2013 MODIS data (Fig. 4) appears to be governed by the relative extent of clean ice and snow surfaces. This aligns with findings from current SMB models, as the majority of variability in the overall Greenland ablation area albedos is driven by the deposition, change, and removal of snow (Alexander et al., 2014; Van Angelen et al., 2012). However, 2012 MODIS albedo distributions cannot be explained by transitions from snow to ice and vice versa. Instead, the 2012 MODIS albedo distributions likely reflect abrupt shifts in ablation area albedos from the exposure of impurities on the ice surface in the so-called "dark-band" region as well as ice crystal growth and expansion of dirty ice areas, even with the presence of a few snowfall events. As such, dust and impurities on Greenland's ice sheet surface can influence surface albedos in the ablation area. The current state of SMB models are capable of simulating albedo as a function of meltwater ponding (Alexander et al., 2014) and impurities from atmospheric dust deposition on snow (Van Angelen et al., 2012). The models might be improved by incorporating the melting out of dust and sediments in outcropped ice layers, found in the dark-band region.

\section{Conclusions}

A first high-quality in situ spectral albedo data set collected along a fixed transect is presented for southwest Greenland's ablation area. Previous studies have attributed an increase in melt season duration, less snowfall accumulation, enhanced snow grain metamorphism rates and melt-albedo feedback as primary mechanisms for lowering ablation area albedos. Here, we demonstrate an additional control on albedos in the ablation area, namely the distribution of distinct surface types such as snow, clean ice, impurity-rich ice, melt ponds, and streams and also examine their modulation on surface ablation. The spatial extent of each of these surface types result in a multi-modal albedo distributions in the ablation area. Analysis of MODIS data suggests that a multi-modal distribution and, consequentially, a shift from light- to dark-dominated surfaces and sensitivity to melting of outcropped ice layers characterize seasonal changes in Greenland's ablation area and therefore melt rates. 
Continued atmospheric warming coinciding with a darkening ice surface will increase the ice sheet surface meltwater production and runoff. Here, we show the importance of the distribution of dirty ice surfaces, which are likely the result of accumulation of impurities melted out from internal ice layers (at longer timescales, e.g., summer 2012) rather than contemporary deposition of atmospherically transported dust (except perhaps at short timescales). Future research should investigate the importance of surface accumulation of impurities and if its surface area can change to significantly influence GrIS albedo and surface ablation. Analysis of spatiotemporal variability in albedos using higher spatial resolution imagery is needed to adequately characterize surface types, particularly for dust and sediment-rich surfaces, to improve our understanding of the contribution of ablation area albedos to GrIS mass loss. 


\section{Appendix A: Field spectroscopy measurements}

At the start of each transect, the ASD was calibrated to current hemispherical atmospheric conditions by orienting the RCR skyward along a nadir-viewing angle. Subsequent measurements were taken with the ASD rotated $180^{\circ}$ to view the ice surface. Under changing sky conditions, the instrument was recalibrated. Each transect consisted of $\sim 100$ sample locations roughly $10 \mathrm{~m}$ apart. Despite changing ice conditions rapidly deteriorating temporary location markers, GPS locations reveal that sample sites in consecutive transects were gathered in close proximity (Fig. 1). While samples were not taken from exactly the same sites, preventing a point-by-point comparison, transect sample distributions and smoothed spatial patterns can be analyzed for change over time. Sample sites along each transect were selected based on distance. If a spectrum site intersected with a stream, melt pond, or cryoconite hole, the nearest ice surface was sampled instead. To capture spectral albedos of different ice surface types, separate measurements of streams, dirty ice, and white ice were collected. At each sample location, five consecutive spectra consisting of 10 dark currents per scan and 10 white reference measurements were recorded and averaged.

Apparent outliers were identified using the Spectral Analysis and Management System software to identify outliers. Outliers were defined as physically unrealistic spectral albedo values $(>1.0)$ and raw spectra that were markedly different to the other spectra across the entire spectral range (visible and near-infrared wavelengths) taken for the same sample. For 16 June, 20 spectra were deemed outliers (total spectra collected $=555$ ); for 19 June, 17 spectra were deemed outliers (total spectra collected $=560$ ); and for 25 June, 12 spectra were deemed outliers (total spectra collected $=480$ ). The outliers for these transect dates comprise less than $4 \%$ of all spectra collected and thus, likely had an insignificant impact on the final albedo calculations. On 17 June, spectra with unrealistic $>1.0$ values were collected, as will be shown in Appendix B. All data from this day were considered low quality and removed from the data set.

\section{Appendix B: Quality control of $\alpha_{\text {ASD }}$ data}

To ensure a high-quality $\alpha_{\mathrm{ASD}}$ data set, an impact assessment of variable cloud conditions (i.e., irregular lighting due to transient clouds) and high SZAs during late afternoon albedo transect collections was made. Key et al. (2001) reported a 4-6\% increase in albedos, on average, under cloudy conditions. Albedo readings have also been reported as unreliable at SZAs beyond $70^{\circ}$ due to an increase in diffuse radiation reaching the ice surface (Schaaf et al., 2011; Stroeve et al., 2005, 2013; Wang et al., 2012).

As a proxy for cloud cover, relative cloud cover (CC) was calculated every second as the ratio of modeled clear-sky and observed incoming solar radiation similar to Box (1997).
Clear-sky incoming shortwave fluxes at the surface were calculated with a solar radiance model (Iqbal, 1988). Model inputs of water vapor content, surface pressure, aerosol optical depth at 380 and $500 \mathrm{~nm}$, and area optical thickness were estimated from the Kangerlussuaq AEROsol Robotic NETwork (AERONET) station (Holben et al., 2001). SZA was also modeled with the solar radiance model using latitude, longitude, time of day, and day of year at the Base Met Station. $\alpha_{\mathrm{ASD}}$ collected under high CC variability and SZAs approaching extreme angles were subsequently removed. Filtering $\alpha_{\text {ASD }}$ data under these criteria ensured the production of a high-quality data set necessary for subsequent analysis.

Cloud cover and radiative conditions varied among transects (Fig. B1). The majority of $\alpha_{\mathrm{ASD}}$ measurements were made at small SZAs ( 10:30-12:00 LT), except on 21 and 24 June, when observations were made in late afternoon (15:30-16:30 and 16:40-17:50 LT, respectively). Incoming solar radiation fluxes exhibited considerable range of diurnal variability (average $662 \pm 83 \mathrm{~W} \mathrm{~m}^{-2}$ ). Outgoing solar radiation displayed a similar range of variability at lower magnitudes (average $239 \pm 18 \mathrm{~W} \mathrm{~m}^{-2}$ ) during transect dates. Derived $\mathrm{CC}$ reveals a daily range in cloud fractions roughly consistent with incoming solar radiation observations which on average remained low $(\sim 0.13)$, indicating that the majority of the transect measurements were collected during nearly cloud-free conditions. During transect times, halfhourly $\alpha_{\text {base }}$ changed linearly with SZA yet remained fairly stable (Fig. B2a). Above $80^{\circ}$ SZA, half-hourly $\alpha_{\text {base }}$ variability increased, confirming that $70^{\circ}$ SZA was a suitable threshold for daily average albedo calculations. Installation tilt and heterogeneous and changing surface conditions likely contributed locally to "unstable" $\alpha_{\text {base }}$ observations at higher SZAs. A hysteresis observed in $\alpha_{\text {top }}$ observations (data not shown) is attributed primarily to a low installation height $(0.5 \mathrm{~m})$ but may also be partly due to changing surface conditions. These effects can compromise the accurate representation of illumination and viewing geometries, resulting in reduced albedo estimates at high SZAs (Kuhn, 1974; Wang et al., 2012; Dumont et al., 2012). As such, Top Met Station measurements, and $\alpha_{\text {base }}$ at SZAs greater than $70^{\circ}$, were excluded for most analyses. Despite its limitations, $\alpha_{\text {top }}$ data were used for $\alpha_{\text {ASD }}$ comparison described below.

A high range of $\mathrm{CC}$ variability, instead of consistently high $\mathrm{CC}$, was found to be responsible for saturating $\alpha_{\mathrm{ASD}}$ readings on 17, 21, and 24 June (Fig. B2b). Continuous recalibration of the ASD instrument on 17 and 24 June was inadequate to overcome variable lighting conditions, resulting in saturated $\alpha_{\text {ASD }}$ readings ( $\left.>1\right)$. During 21 June, $\alpha_{\text {ASD }}$ data did not saturate despite variable sky conditions $(0.01-0.52 \mathrm{CC}$ range). Variable cloud conditions on 17, 21, and 24 of June effectively increased the amount of downwelling long-wave radiation relative to shortwave radiation available at the surface, of which the net effect results in a larger portion of solar radiation available to be reflected by the ice surface (Grenfell and Perovich, 2004; Román et al., 2010; Wang et al., 2012). 


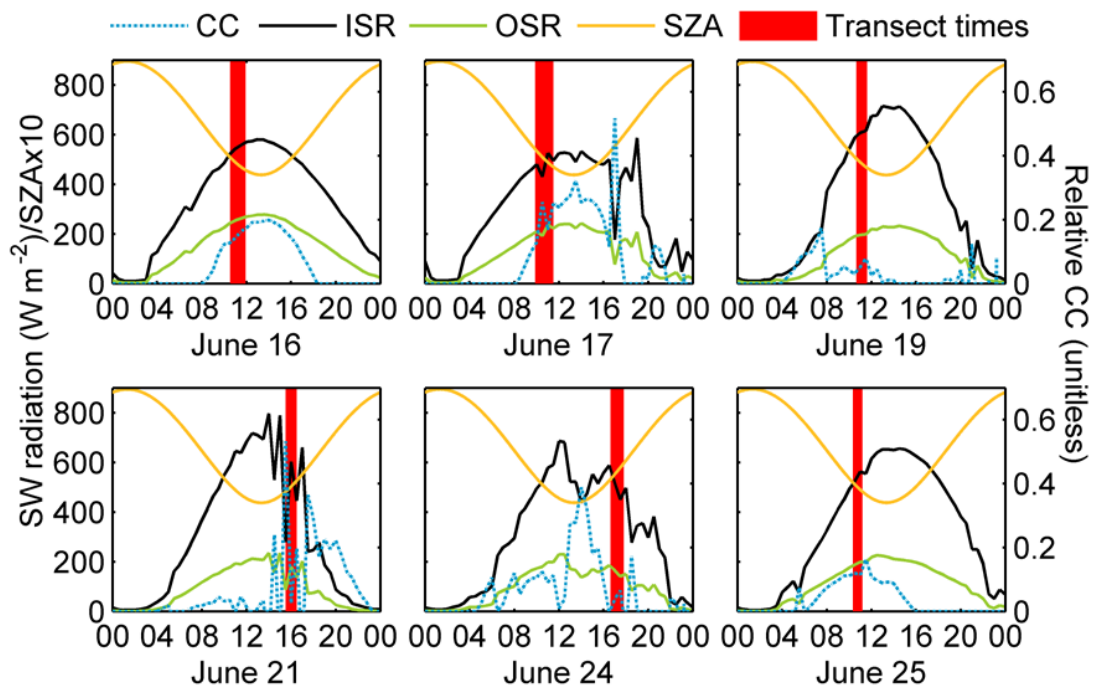

Figure B1. Radiative conditions during transect dates at the Base Met Station, including incoming solar radiation (ISR, black line), outgoing solar radiation (OSR, green line; left $y$ axis), modeled relative cloud cover (CC, blue stippled line; right $y$ axis), and solar zenith angles (SZA, yellow line right axis). Red shaded regions show $\alpha_{\text {ASD }}$ data collection times.
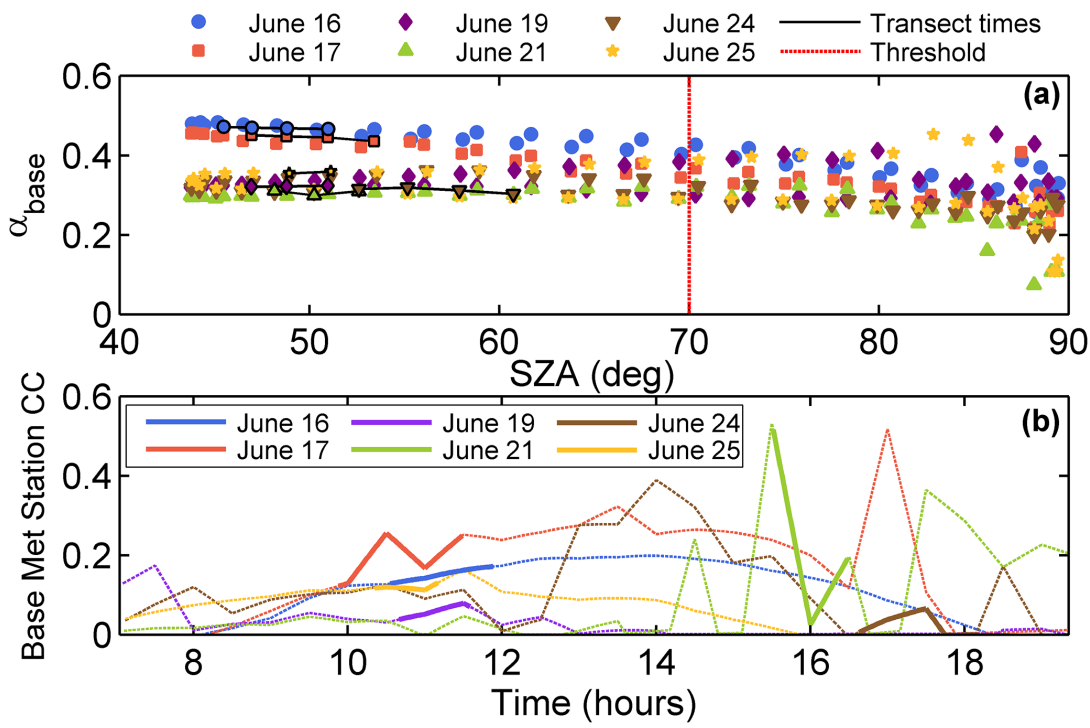

Figure B2. (a) Half-hourly broadband $\alpha_{\text {base }}$ measurements as a function of SZA. Symbols and colors correspond to transect dates. Transect times correspond to the black line. A SZA threshold at $70^{\circ}$ is represented by the red stipple line. (b) Relative CC determined at $\alpha_{\text {base }}$ as a function of time during transect dates. Symbols and colors correspond to transect dates. Transect times correspond to bold lines.

This can translate to an increase in spectral albedo estimates by $\sim 0.06$ over active melting ice surfaces (Grenfell and Perovich, 2004).

By removing the majority of shortcomings and uncertainties identified in transect radiative and surface conditions, a high-quality albedo data set was produced. Optimal SZA, $\mathrm{CC}$, and radiative conditions were observed for 16,19 , and 25 June. $\alpha_{\text {ASD }}$ data collected on 17, 21, and 24 June were identified as low quality based on their dependence on SZA, $\mathrm{CC}$ variability, and issues with albedo saturation and were subsequently removed from further analysis (Fig. B2). The first and last high-quality $\alpha_{\mathrm{ASD}}$ measurements closest to the AWSs were compared and reveal that they agree reasonably well with $\alpha_{\text {base }}$ and $\alpha_{\text {top }}$ data (Fig. B3). As much as $62 \%$ of $\alpha_{\mathrm{ASD}}$ variance is explained by $\alpha_{\text {base }}$ and $\alpha_{\mathrm{top}}$ $\left(\alpha_{\mathrm{ASD}}=0.27 \alpha_{\mathrm{MET}}+0.46\right.$, where $\alpha_{\mathrm{MET}}$ is $\alpha_{\text {base }}$ and $\alpha_{\text {top }}$ combined). The discrepancy is likely due to differences in exact sample locations and instrumentation. Table 1 provides summary statistics related to high-quality $\alpha_{\mathrm{ASD}}$ and transect conditions. 


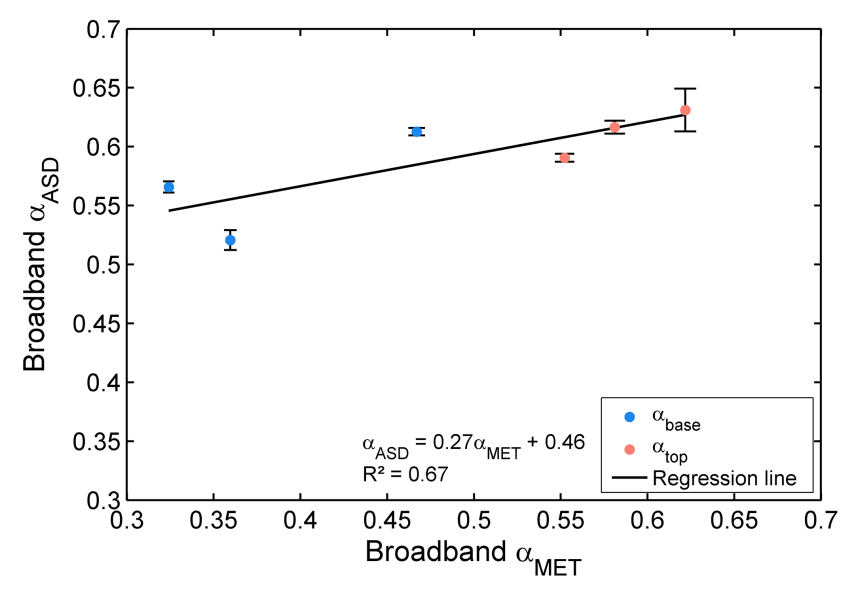

Figure B3. Broadband $\alpha_{\text {base }}$ (blue dots) and $\alpha_{\text {top }}$ (pink dots) vs. $\alpha_{\text {ASD }}$ and $\alpha_{\text {MET }}$ (i.e., both $\alpha_{\text {base }}$ and $\alpha_{\text {top }}$ ) measurements fitted to a linear regression equation $\left(R^{2}=0.67\right)$. The value of $\alpha_{\mathrm{ASD}}$ error is based on the standard deviation of individual $\alpha_{\text {ASD }}$ measurements.

\section{Appendix C: Installation of meteorological stations}

The Top Met Station was installed upon a homogeneous clean ice surface, and the Base Met Station was installed above a heterogeneous surface of mixed clean and dirty ice. Both stations measured solar radiation fluxes every $0.5 \mathrm{~h}$ at 300-1100 nm, using S-LIB-M003 silicon pyranometers and a U30 data logger (Table $\mathrm{C} 1 ; \pm 5 \%$ or $10 \mathrm{~W} \mathrm{~m}^{-2}$ precision; Onset Computer Corp., 2010) from 8 to 26 June. Sensors were attached to a pole drilled into the ice at $1.5 \mathrm{~m}$ above the surface and were kept relatively constant at this height but occasionally tilted off level. After a period of heavy melting, the Top Met Station was re-drilled and installed at $0.5 \mathrm{~m}$ height and remained at this height as melting seized. A very large hysteresis in $\alpha_{\text {top }}$ as a function of SZA suggests that the low installation height resulted in $\alpha_{\text {top }}$ errors due to a disproportionally large influence of surface roughness on its measurements. Despite not having observed tilt information for the AWSs, we use a theoretical tilt (see Fig. 3b) in Van den Broeke et al. (2004) to provide a reasonable uncertainty range. Assuming a tilt of $1^{\circ}$ on 18 January at Kohnen station, Antarctica $\left(75^{\circ} \mathrm{S}, 0^{\circ}\right)$ is associated with $\sim 15 \mathrm{~W} \mathrm{~m}^{-2}$ offset in net shortwave at noon local time. This is associated with an absolute error of $5 \%$ with a tilt of $1^{\circ}$. Here, we assume double the uncertainty $( \pm 10 \%)$.
Table C1. Meteorological station sites and associated variables.

\begin{tabular}{|c|c|c|c|c|c|}
\hline Site & Latitude & Longitude & $\begin{array}{l}\text { Elevation } \\
\text { (m) }\end{array}$ & $\begin{array}{l}\text { Start } \\
\text { date }\end{array}$ & $\begin{array}{l}\text { End } \\
\text { date }\end{array}$ \\
\hline Base Met & 67.151629 & 50.027993 & 511.3 & 8 & 26 \\
\hline Station & & & & June & June \\
\hline Top Met & 67.146857 & 50.001186 & 586.0 & 14 & 26 \\
\hline Station & & & & June & June \\
\hline
\end{tabular}


Acknowledgements. S. E. Moustafa, A. K. Rennermalm, L. C. Smith and J. R. Mioduszewski were funded by NASA grant NNX11AQ38G and NNX14AH93G. S. E. Moustafa was also funded by NASA Earth and Space Science Fellowship Program NNX12AN98H. Additional funding was provided by Rutgers University faculty research grant. Field logistical support was provided by $\mathrm{CH} 2 \mathrm{M}$ Hill Polar Field Services and the Kangerlussuaq International Science Station. The authors would like to thank A. Pope M. S. Pelto, and K. Casey as well as two anonymous reviewers for valuable feedback and commentary.

Edited by: M. van den Broeke

\section{References}

Alexander, P. M., Tedesco, M., Fettweis, X., van de Wal, R. S. W., Smeets, C. J. P.cP., and van den Broeke, M. R.: Assessing spatiotemporal variability and trends in modelled and measured Greenland Ice Sheet albedo (2000-2013), The Cryosphere, 8, 2293 2312, doi:10.5194/tc-8-2293-2014, 2014

Bøggild, C. E., Brandt, R. E., Brown, K. J., and Warren, S. G.: The ablation zone in northeast Greenland: ice types, albedos and impurities, J. Glaciol., 56, 101-113, doi:10.3189/002214310791190776, 2010.

Box, J. E., Fettweis, X., Stroeve, J. C., Tedesco, M., Hall, D. K., and Steffen, K.: Greenland ice sheet albedo feedback: thermodynamics and atmospheric drivers, The Cryosphere, 6, 821-839, doi:10.5194/tc-6-821-2012, 2012.

Chandler, D. M., Alcock, J. D., Wadham, J. L., Mackie, S. L., and Telling, J.: Seasonal changes of ice surface characteristics and productivity in the ablation zone of the Greenland Ice Sheet, The Cryosphere, 9, 487-504, doi:10.5194/tc-9-487-2015, 2015.

Cuffey, K. and Paterson, W. S. B.: The Physics of Glaciers, 4th Edn., Elsevier Inc., Burlington and Oxford, 2010.

Dozier, J., Painter, T. H., Rittger, K. and Frew, J. E.: Timespace continuity of daily maps of fractional snow cover and albedo from MODIS, Adv. Water Resour., 31, 1515-1526, doi:10.1016/j.advwatres.2008.08.011, 2008.

Dumont, M., Gardelle, J., Sirguey, P., Guillot, A., Six, D., Rabatel, A., and Arnaud, Y.: Linking glacier annual mass balance and glacier albedo retrieved from MODIS data, The Cryosphere, 6, 1527-1539, doi:10.5194/tc-6-1527-2012, 2012.

Dumont, M., Brun, E., Picard, G., Michou, M., Libois, Q., Petit, J., Geyer, M., Morin, S., and Josse, B.: Contribution of lightabsorbing impurities in snow to Greenland's darkening since 2009, Nat. Geosci., 7, 509-512, doi:10.1038/ngeo2180, 2014.

Ettema, J., van den Broeke, M. R., van Meijgaard, E., van de Berg, W. J., Box, J. E., and Steffen, K.: Climate of the Greenland ice sheet using a high-resolution climate model - Part 1: Evaluation, The Cryosphere, 4, 511-527, doi:10.5194/tc-4511-2010, 2010.

Fettweis, X.: Reconstruction of the 1979-2006 Greenland ice sheet surface mass balance using the regional climate model MAR, The Cryosphere, 1, 21-40, doi:10.5194/tc-1-21-2007, 2007.

Fettweis, X., Tedesco, M., van den Broeke, M., and Ettema, J.: Melting trends over the Greenland ice sheet (1958-2009) from spaceborne microwave data and regional climate models, The Cryosphere, 5, 359-375, doi:10.5194/tc-5-359-2011, 2011.

Fitzgerald, P. W., Bamber, J. L., Ridley, J. K., and Rougier, J. C. Exploration of parametric uncertainty in a surface mass balance model applied to the Greenland ice sheet, J. Geophys. Res., 117, F01021, doi:10.1029/2011JF002067, 2012.

Gorter, W., van Angelen, J. H., Lenaerts, J. T. M. and van den Broeke, M. R.: Present and future near-surface wind climate of Greenland from high resolution regional climate modelling, Clim. Dyn., 42, 1595-1611, doi:10.1007/s00382-013-1861-2, 2014.

Grenfell, T. C. and Perovich, D. K.: Seasonal and spatial evolution of albedo in a snow-ice-land-ocean environment, J. Geophys. Res., 109, C01001, doi:10.1029/2003JC001866, 2004.

Hall, D. K., Riggs, G. A., and Salomonson, V. V.: MODIS Snow and Sea Ice Products 2006: Earth Science Satellite Remote Sensing - Volume I: Science and Instruments, edited by: Qu, J. J., Gao, W., Kafatos, M., Murphy, R. E., and Salomonson, V. V., Springer, New York, 154-181, 2006.

Hall, D. K., Comiso, J. C., DiGirolamo, N. E., Shuman, C. A., Box, J. E., and Koenig, L. S.: Variability in the surface temperature and melt extent of the Greenland ice sheet from MODIS, Geophys. Res. Lett., 40, 2114-2120, doi:10.1002/grl.50240, 2013.

Hanna, E., Fettweis, X., Mernild, S. H., Cappelen, J., Ribergaard, M. H., Shuman, C. A., Steffen, K., Wood, L., and Mote, T. L.: Atmospheric and oceanic climate forcing of the exceptional Greenland ice sheet surface melt in summer 2012, Int. J. Climatol., 34, 1022-1037, doi:10.1002/joc.3743, 2014.

Holben, N., Tanr, D., Smirnov, A., Eck, T. F., Slutsker, I., Newcomb, W. W., Schafer, J. S., Chatenet, B., Lavenu, F., Kaufman, J., Castle, J. Vande, Setzer, A., Markham, B., Clark, D., Halthore, R., Karneli, A., Neill, N. T. O., Pietras, C., Pinker, T., Voss, K., and Zibordi, G.: An emerging ground-based aerosol climatology?: aerosol optical depth from AERONET, J. Geophys. Res., 106, 12067-12097, 2001.

Hubbard, B. and Glasser, N. F.: Field techniques in glaciology and glacial geomorphology, John Wiley \& Sons, 2005.

Iqbal, M.: Spectral and total sun radiance under cloudless skies, in: Physical Climatology for Solar and Wind Energy, edited by: Guzzi, R. and Justus, C. G., World Scientific, Singapore, 196242, 1988.

Keegan, K. M., Albert, M. R., McConnell, J. R., and Baker, I.: Climate change and forest fires synergistically drive widespread melt events of the Greenland Ice Sheet., P. Natl. Acad. Sci. USA., 111, 7964-7967, doi:10.1073/pnas.1405397111, 2014.

Klein, A. G. and Stroeve, J.: Development and validation of a snow albedo algorithm for the MODIS instrument, Annals of Glaciol., 34, 45-52, 2002.

Knap, W. H. and Oerlemans, J.: The surface albedo of the Greenland ice sheet: satellite derived and in situ measurements in the Sendre Stromfjord area during the 1991 melt season, J. Glaciol., 42, 364-374, 1996

Konzelmann, T. and Braithwaite, R. J.: Variations of ablation, albedo and energy balance at the margin of the Greenland ice sheet, Kronprins Christian Land, eastern north Greenland, J. Glaciol., 41, 174-182, 1995

Kuhn, M.: Anisotropic reflection from sastrugi fields, Antarc. J. US 9, 123-125, 1974 
Lampkin, D. J. and VanderBerg, J.: Supraglacial melt channel networks in the Jakobshavn Isbrae region during the 2007 melt season, Hydrol. Process., doi:10.1002/hyp.10085, 2013.

Legleiter, C. J., Tedesco, M., Smith, L. C., Behar, A. E., and Overstreet, B. T.: Mapping the bathymetry of supraglacial lakes and streams on the Greenland ice sheet using field measurements and high-resolution satellite images, The Cryosphere, 8, 215-228, doi:10.5194/tc-8-215-2014, 2014.

Lenaerts, J. T. M., Smeets, C. J. P. P., Nishimura, K., Eijkelboom, M., Boot, W., van den Broeke, M. R., and van de Berg, W. J.: Drifting snow measurements on the Greenland Ice Sheet and their application for model evaluation, The Cryosphere, 8, 801814, doi:10.5194/tc-8-801-2014, 2014.

Lhermitte, S., Abermann, J., and Kinnard, C.: Albedo over rough snow and ice surfaces, The Cryosphere, 8, 1069-1086, doi:10.5194/tc-8-1069-2014, 2014.

Van Meijgaard, E., van Ulft, L. H., Van de Berg, W. J., Bosveld, F. C., Van den Hurk, B., Lenderink, G., and Siebesma, A. P.: The KNMI regional atmospheric climate model RACMO version 2.1, Tech. Rep. 302, Royal Netherlands Meteorological Institute, De Bilt, 2008.

Mernild, S. H. and Liston, G. E.: Greenland freshwater runoff. Part II: Distribution and trends, 1960-2010, J. Climate, 25, 60156035, doi:10.1175/JCLI-D-11-00592.1, 2012.

Nghiem, S. V., Hall, D. K., Mote, T. L., Tedesco, M., Albert, M. R., Keegan, K., Shuman, C. A., DiGirolamo, N. E., and Neumann, G.: The extreme melt across the Greenland Ice Sheet in 2012, Geophys. Res. Lett., 39, 1-6, doi:10.1029/2012GL053611, 2012.

Onset Computer Corp.: Silicon Pyranometer Smart Sensor (Part \# S-LIB-M003), available at: http://wpc.306e. edgecastcdn.net/80306E/onsetcomp_com/files/manual_pdfs/ 6708-D-MAN-S-LIB.pdf (last access: 14 August 2013), 2010.

Rae, J. G. L., Aðalgeirsdóttir, G., Edwards, T. L., Fettweis, X., Gregory, J. M., Hewitt, H. T., Lowe, J. A., Lucas-Picher, P., Mottram, R. H., Payne, A. J., Ridley, J. K., Shannon, S. R., van de Berg, W. J., van de Wal, R. S. W., and van den Broeke, M. R.: Greenland ice sheet surface mass balance: evaluating simulations and making projections with regional climate models, The Cryosphere, 6, 1275-1294, doi:10.5194/tc-6-1275-2012, 2012.

Rennermalm, A. K., Moustafa, S. E., Mioduszewski, J., Chu, V. W., Forster, R. R., Hagedorn, B., Harper, J. T., Mote, T. L., Robinson, D. A., Shuman, C. A., Smith, L. C. and Tedesco, M.: Understanding Greenland ice sheet hydrology using an integrated multi-scale approach, Environ. Res. Lett., 8(1), 015017, doi:10.1088/1748-9326/8/1/015017, 2013.

Román, M. O., Schaaf, C. B., Lewis, P., Gao, F., Anderson, G. P., Privette, J. L., Strahler, A. H., Woodcock, C. E., and Barnsley, M.: Assessing the coupling between surface albedo derived from MODIS and the fraction of diffuse skylight over spatiallycharacterized landscapes, Remote Sens. Environ., 114, 738-760, doi:10.1016/j.rse.2009.11.014, 2010.

Schaaf, C. B., Liu, J., Gao, F., and Strahler, A. H.: Aqua and Terra MODIS albedo and reflectance anisotropy products, in: Remote Sensing and Global Environmental Change, 549-561, Springer, New York, 2011.

Schaepman-Strub, G., Schaepman, M. E., Painter, T. H., Dangel, S., and Martonchik, J. V.: Reflectance quantities in optical remote sensing - definitions and case studies, Remote Sens. Environ., 103, 27-42, doi:10.1016/j.rse.2006.03.002, 2006.

Smith, L. C., Chu, V. W., Yang, K., Gleason, C. J., Pitcher, L. H., Rennermalm, A. K., Legleiter, C. J., Behar, A. E., Overstreet, B. T., Moustafa, S. E., Tedesco, M., Forster, R. R., LeWinter, A. L., Finnegan, D. C., Sheng, Y., and Balog, J.: Supraglacial rivers on the Greenland Ice Sheet, P. Natl. Acad. Sci. USA, doi:10.1073/pnas.1413024112, 2015.

Stroeve, J., Box, J. E., Gao, F., Liang, S., Nolin, A., and Schaaf, C.: Accuracy assessment of the MODIS 16-day albedo product for snow: comparisons with Greenland in situ measurements, Remote Sens. Environ., 94, 46-60, doi:10.1016/j.rse.2004.09.001, 2005.

Stroeve, J. C., Box, J. E., and Haran, T.: Evaluation of the MODIS (MOD10A1) daily snow albedo product over the Greenland Ice Sheet, Remote Sens. Environ., 105, 155-171, doi:10.1016/j.rse.2006.06.009, 2006.

Stroeve, J., Box, J. E., Wang, Z., Schaaf, C., and Barrett, A.: Re-evaluation of MODIS MCD43 Greenland albedo accuracy and trends, Remote Sens. Environ., 138, 199-214, doi:10.1016/j.rse.2013.07.023, 2013.

Tedesco, M., Fettweis, X., van den Broeke, M. R., van de Wal, R. S. W., Smeets, C. J. P. P., van de Berg, W. J., Serreze, M. C., and Box, J. E.: The role of albedo and accumulation in the 2010 melting record in Greenland, Environ. Res. Lett., 6, 014005, doi:10.1088/1748-9326/6/1/014005, 2011.

Tedesco, M., Fettweis, X., Mote, T., Wahr, J., Alexander, P., Box, J. E., and Wouters, B.: Evidence and analysis of 2012 Greenland records from spaceborne observations, a regional climate model and reanalysis data, The Cryosphere, 7, 615-630, doi:10.5194/tc-7-615-2013, 2013.

Tedesco, M., Box, J. E., Cappelen, J., Fettweis, X., Jensen, T., Mote, T. L., Rennermalm, A. K., Smith, L. C., van de Wal, R. S. W., and Wahr, J.: The Arctic: Greenland Ice Sheet in "State of the Climate 2013.” Bull. Am. Meteorol. Soc., 95, S136-S137, 2014.

Van Angelen, J. H., Lenaerts, J. T. M., Lhermitte, S., Fettweis, X., Kuipers Munneke, P., van den Broeke, M. R., van Meijgaard, E. and Smeets, C. J. P. P.: Sensitivity of Greenland Ice Sheet surface mass balance to surface albedo parameterization: a study with a regional climate model, The Cryosphere, 6, 1175-1186, doi:10.5194/tc-6-1175-2012, 2012.

van den Broeke, M., van As, D., Reijmer, C., and van de Wal, R.: Assessing and improving the quality of unattended radiation observations in Antarctica, J. Atmos. Ocean. Tech., 21, 1417-1431, doi:10.1175/1520-0426(2004)021<1417:AAITQO>2.0.CO;2, 2004.

van den Broeke, M., Smeets, P., Ettema, J., van der Veen, C., van de Wal, R., and Oerlemans, J.: Partitioning of melt energy and meltwater fluxes in the ablation zone of the west Greenland ice sheet, The Cryosphere, 2, 179-189, doi:10.5194/tc-2179-2008, 2008.

van den Broeke, M. R., Smeets, C. J. P. P., and van de Wal, R. S. W.: The seasonal cycle and interannual variability of surface energy balance and melt in the ablation zone of the west Greenland ice sheet, The Cryosphere, 5, 377-390, doi:10.5194/tc-5-377-2011, 2011.

Van de Wal, R. S. W., Boot, W., Smeets, C. J. P. P., Snellen, H., van den Broeke, M. R., and Oerlemans, J.: Twenty-one years of mass balance observations along the K-transect, West Green- 
land, Earth Syst. Sci. Data, 4, 31-35, doi:10.5194/essd-4-312012, 2012.

Wang, Z., Schaaf, C. B., Chopping, M. J., Strahler, A. H., Wang, J., Román, M. O., Rocha, A. V., Woodcock, C. E., and Shuai, Y.: Evaluation of Moderate-resolution Imaging Spectroradiometer (MODIS) snow albedo product (MCD43A) over tundra, Remote Sens. Environ., 117, 264-280, doi:10.1016/j.rse.2011.10.002, 2012.

Warren, S. G., Brandt, R. E., and O'Rawe Hinton, P.: Effect of surface roughness on bidirectional reflectance of Antarctic snow, J. Geophys. Res., 103, 25789, doi:10.1029/98JE01898, 1998.

Wientjes, I. G. M. and Oerlemans, J.: An explanation for the dark region in the western melt zone of the Greenland ice sheet, The Cryosphere, 4, 261-268, doi:10.5194/tc-4-261-2010, 2010.

Wientjes, I. G. M., Van de Wal, R. S. W., Reichart, G. J., Sluijs, A., and Oerlemans, J.: Dust from the dark region in the western ablation zone of the Greenland ice sheet, The Cryosphere, 5, 589601, doi:10.5194/tc-5-589-2011, 2011.
Wright, P., Bergin, M., Dibb, J., Lefer, B., Domine, F., Carman, T. Carmagnola, C., Dumont, M., Courville, Z., Schaaf, C., and Wang, Z.: Comparing MODIS daily snow albedo to spectral albedo field measurements in Central Greenland, Remote Sens. Environ., 140, 118-129, doi:10.1016/j.rse.2013.08.044, 2014.

Yang, K. and Smith, L. C.: Supraglacial streams on the Greenland Ice Sheet delineated from combined spectral-shape information in high-resolution satellite imagery, IEEE Geosci. Remote Sens. Lett., 10, 801-805, doi:10.1109/LGRS.2012.2224316, 2013.

Zhuravleva, T. B. and Kokhanovsky, A. A.: Influence of surface roughness on the reflective properties of snow, J. Quant. Spectrosc. Radiat. Transf., 112, 1353-1368, doi:10.1016/j.jqsrt.2011.01.004, 2011. 